Article

\title{
Conceptual Advanced Transport Aircraft Design Configuration for Sustained Hypersonic Flight
}

\author{
Can Alkaya, Ashish Alex Sam * and Apostolos Pesyridis \\ Department of Mechanical and Aerospace Engineering, College of Engineering and Design, Brunel University \\ London, Uxbridge, London UB8 3PH, UK; 1108868@brunel.ac.uk (C.A.); a.pesyridis@brunel.ac.uk (A.P.) \\ * Correspondence: ashish.sam@brunel.ac.uk; Tel.: +44-1895-267-901
}

Received: 30 June 2018; Accepted: 24 August 2018; Published: 1 September 2018

\begin{abstract}
The conceptual aircraft design and its integration with a combined cycle engine for hypersonic cruise at Mach 8 is documented in this paper. The paper describes the process taken to develop a hypersonic aircraft from a conceptual approach. The discussion also includes the design and CFD analysis of the integrated combined cycle engine. A final conceptual hypersonic transport aircraft with an integrated combined cycle engine was achieved through this study. According to the analysis carried out, the aircraft is able to take-off and land at the airports it is intended to be used and will be able to generate enough thrust to sustain hypersonic cruise at an altitude of $30 \mathrm{~km}$.
\end{abstract}

Keywords: hypersonic aircraft; CFD; preliminary design

\section{Introduction}

Interest and demand in commercial supersonic and hypersonic travel is rising with more aerospace companies investing into new engine technologies and developing concept aircraft designs capable of supersonic and hypersonic travel. Companies such as Boeing, Airbus, Reaction Engines, and Lockheed-Martin have all produced conceptual designs for commercial hypersonic travel [1].

Most concept aircraft use a combination of different types of engines to achieve the full flight profile, however, some concept aircraft incorporates the use of combined cycle engines to achieve the full flight speed range from 0 Mach to 5+ Mach. The Reaction Engine concept does just that. It uses the Sabre Jet engine to take off from a runway and accelerate to Mach 5 before switching to rocket mode to propel the aircraft beyond Mach 5 [2].

The idea of having a 'combined cycle' engine which achieves the full flight profile is very advantageous for a more efficient and economical hypersonic flight and should be investigated further to develop new ideas and technologies to help commercialise hypersonic travel. The objective of the present work is to develop a commercial transport aircraft with an integrated combined cycle engine for hypersonic cruise at Mach 8. The paper involves the design of the aircraft from its conceptual design to the Computational Fluid Dynamics (CFD) analysis of the hypersonic aircraft integrated with the combined cycle engine.

\section{Hypersonic Flows}

The design criteria for any type of aircraft are governed by the regime of the flow which the aircraft is going to encounter. A streamlined body is the main criterion in the design of a subsonic aircraft, whereas in a supersonic/hypersonic aircraft design it is the reduction of wave drag. Therefore, to design an effective hypersonic vehicle, one must have an in-depth understanding of the hypersonic flow.

There are certain physical phenomena that essentially differentiate the hypersonic flows as compared to the supersonic flows. At hypersonic speeds, drag and aerodynamic heating becomes very 
important. The maximum temperature that a space vehicle experiences in its hypersonic flight rises far beyond the maximum temperature limit of any material. The design of a hypersonic aircraft is, therefore, dominated by aerodynamic surface heating where the reduction of heat transfer rate plays an important role [3]. Consequently, cooling technologies play a very important role in the structural integrity and the success of any hypersonic aircraft that is going to be designed.

The maximum temperature loads experienced during hypersonic flight can be slightly reduced by the shape of the aircraft. Imposed bluntness on the aircraft nose can lessen the oncoming heat load, however, increased wave drag is the consequence of an imposed bluntness. The increased drag has a knock-on effect to the required fuel for the mission as the propulsion system now must increase the thrust to overcome the increase in drag. Hence, numerous wave drag reduction techniques and a balance between imposed bluntness and drag should be sought after in any hypersonic aircraft design [3]. Additionally, at the upper levels of the atmosphere at hypersonic speeds real gas effects play a very important role in physics of the external flows. At high speeds, heat is generated due to high skin friction. This excites molecules in the air and releases their vibrational energy. This, in turn, increases the internal energy of these molecules [3,4]. The development of the entropy layer and the viscous-inviscid interaction are the other phenomena that exist in hypersonic flows $[5,6]$.

Engine integration for a hypersonic aircraft is crucial. A proper aerodynamic integration of the entire propulsion system is required to achieve an efficient hypersonic flight. This is needed due to the large airflow requirements at high speeds. This integration includes every aspect of the propulsion system from the aircraft structure to the materials and thermal management. To capture the required airflow for sustained hypersonic flight, the entire forebody under surface of the aircraft is used as a compression ramp shaped to obtain the maximum efficiency. In addition to this, the entire afterbody under surface of the aircraft is designed to be used as an expansion nozzle to obtain enough thrust for hypersonic flight $[7,8]$.

When performing engine integration onto aircraft, one must consider the effect of the aircraft on the engine performance, as well as the effect of the engine on the aircraft. For example, at Mach numbers lower than the designed cruise speeds, the shock waves and the compressed flow moves away from the aircraft inlet so some of the compressed air is not captured. As the aircraft manoeuvres, the shocks move closer on to the lifting side which, again, effects the air capture [8,9].

Another significant integration problem is that the aircraft pitching moment is affected with flight Mach number. The higher mass capture achieved at high Mach numbers allow the engine to produce higher pressures on the nozzle than that on the forebody produced by aerodynamic compression. This results in a pitch down motion. However, this effect is reversed at lower Mach numbers as the aircraft tends to have a nose-up pitching moment. From this, it can be deduced that the aircraft pitching moment and trim requirement will constantly change with the change in thrust as there will be a constant change in the nozzle pressures while the inlet forces are practically constant [9].

\section{Methodology}

\subsection{Computational Methodology}

As there are multiple phenomena that occur in hypersonic flow, the CFD modelling adopted should account for the actual flow physics. Reynolds-Averaged Navier Stokes (RANS) methods are mostly used in hypersonic flow applications. The reliability of the CFD results are primarily determined by the accuracy of the RANS turbulence models used in the computation of such flows [10]. The different modules available with the commercially available software Ansys Fluent were used for modelling, meshing and computations.

Figure 1 shows the 3-D mesh for the integrated aircraft and engine and the 3-D mesh specifications are described in Table 1. The total number mesh elements specified in Table 1 was established based on a grid sensitivity analysis. The 3-D aircraft model was tested using approximately 506,000, 2.3 million, 5.6 million, 10 million, and 16 million elements to analyse the results. The results were found to 
be identical after 5.6 million elements and hence was selected for the present analysis. A detailed description of the numerical methodology adopted is extensively reported in Baidya et al. [11], Neill and Pesyridis [12], and Sen et al. [13].

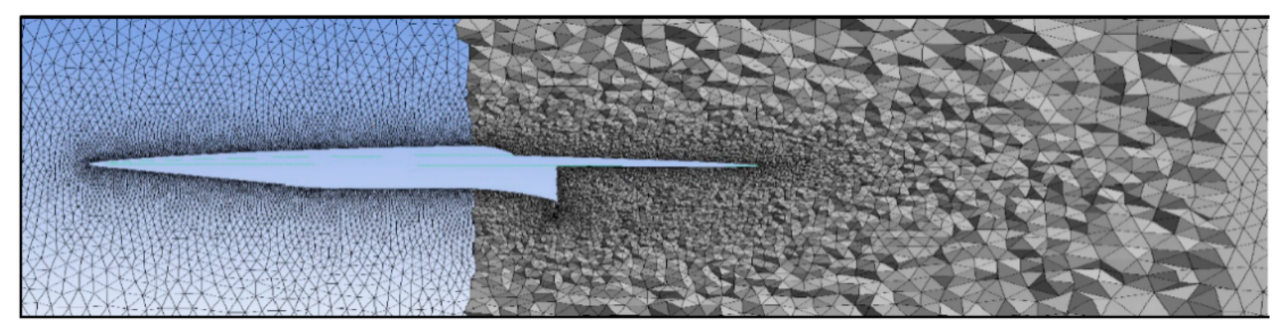

Figure 1. 3-D mesh for the integrated aircraft and engine.

Table 1. 3-D mesh statistics for the integrated aircraft and engine.

\begin{tabular}{cc}
\hline Elements & $5,591,991$ \\
Average skewness & 0.215 \\
Average orthogonal quality & 0.866 \\
\hline
\end{tabular}

A density-based solver was selected as the flow conditions being tested are both compressible and high speed. Density based solvers have also been found to give better results in supersonic and hypersonic flows. The shear stress transport (SST) k- $\omega$ model was adopted to model the turbulence. Turbulence in the pressure far-field boundary condition was specified using 'intensity and viscosity ratio' and was set to $1 \%$ and 1 respectively for supersonic and hypersonic flows. For subsonic flows, they were kept default at $5 \%$ and 10, respectively. Ideal gas was selected for the fluid domain where the Sutherland model was selected for viscosity formulation as it is well suited for compressible, high speed flows [14]. The pressure far field boundary condition was used and was specified by the flow Mach number and static pressure. Aerofoil analysis were done at sea level conditions, however, the aircraft simulations for supersonic and hypersonic speeds were carried out at intended cruise altitude of $100,000 \mathrm{ft}$. The convergence criteria for all the conservation equations was kept to be $10^{-3}$. Convergence of lift and drag values were monitored.

The numerical methodology adopted in the present study was validated with the results of North American X-15 available in the open literature. The drag coefficient from the CFD results was compared with the published drag coefficient values for the X-15 [15]. The CFD results showed a drag coefficient of 0.98 compared to the published data of 0.95 , which resulted in an error margin of $3.1 \%$.

Furthermore, two studies from the 'NPARC Alliance Verification and Validation Archive' was used to validate the CFD methodology [16]. These studies have been simulated using WIND-US tools and has either exact analytical or experimental results along with the simulation results. One of the studies tested was a flow at Mach 7 over a 15 degree ramp and the other test done was simulating Mach 2 flow over 15 degree wedge. The shock angle was observed on both cases. The CFD setup performed exceptionally well at supersonic speeds and achieved exact results for the shock angles. At hypersonic speeds however, there was an error margin of $4.76 \%$ when the shock angle was of concern. To better understand shock angle error at different Mach numbers, a series of 2-D simulations were done using the planform geometry of the conceptual aircraft. The results were then compared with shockwave theory using the compressible flow tables and graphs (Figure 2). 


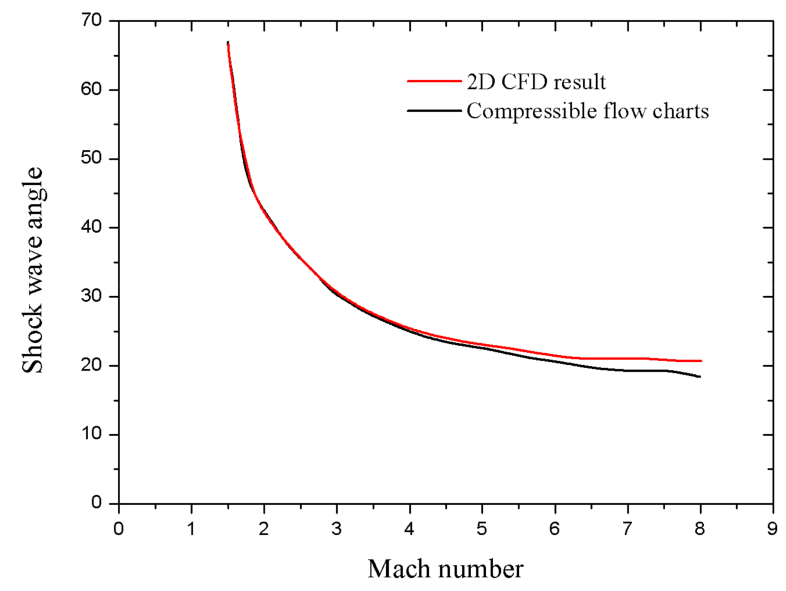

Figure 2. Comparison of CFD results with shockwave theory.

Looking at the results, the CFD setup simulates the shock angles perfectly until Mach 4 . At Mach 4, results start to deviate rapidly. When the flow speed is increased to Mach 8, the error margin becomes $10 \%$. This shows that although the CFD setup accurately models supersonic flows, it needs slightly more adjustment to achieve better results at hypersonic speeds.

Furthermore, although the CFD results matched the results in the validation studies, it was only the shockwave angle that was monitored. Therefore, to better understand the error breakdown and further validate the CFD setup, the error margin for flow parameters such as temperature, pressure and speed was determined.

It may be observed from tables (Tables 2 and 3) that as the flow speed is increased to low hypersonic speeds, the error in the results increases. The main cause of error and its increase in hypersonic flows is due to the physical models used. The turbulence models use Navier-Stokes approximations to model the flow where the model accounts for the effects of the turbulence rather than simulating it directly. This contributes to the overall error in the results and has a greater effect for high speed flows [17]. Nonetheless, turbulence can be effectively simulated at high speed flows in the low hypersonic regions, however, due to the range of length and timescales associated with high speed simulations, it is computationally very expensive even with today's computers [17].

Table 2. Comparison of CFD results with shockwave theory for Mach 2.

\begin{tabular}{cccc}
\hline Physical Property & Shockwave Theory & CFD Results & Error \% \\
\hline M2 (Mach number after shock) & 1.564 & 1.54 & $1.5 \%$ \\
P2 (Pressure after shock) & $25,299.8 \mathrm{~Pa}$ & $25,675.24 \mathrm{~Pa}$ & $1.48 \%$ \\
T2 (Temperature after shock) & $276.032 \mathrm{~K}$ & $278 \mathrm{~K}$ & $0.71 \%$ \\
Shock angle & 42 & 42 & $0 \%$ \\
\hline
\end{tabular}

Table 3. Comparison of CFD results with shockwave theory for Mach 8.

\begin{tabular}{cccc}
\hline Physical Property & Shockwave Theory & CFD Results & Error \% \\
\hline M2 (Mach number after shock) & 5.54 & 5.12 & $7.58 \%$ \\
P2 (Pressure after shock) & $0.7951 \mathrm{~Pa}$ & $0.76 \mathrm{~Pa}$ & $4.41 \%$ \\
T2 (Temperature after shock) & $478.52 \mathrm{~K}$ & $450 \mathrm{~K}$ & $5.96 \%$ \\
Shock angle & 18 & 20 & $10 \%$ \\
\hline
\end{tabular}

\subsection{Aircraft Design}

The process of designing an aircraft is typically divided into three distinct phases. These are the conceptual design, the preliminary design, and the detail design (Figure 3). Each phase has 
its own unique characteristics and its influence on the final output. All three phases involve some aspect of aerodynamic, propulsion, and structural design, and the design of some of the aircraft systems. The conceptual design phase includes development of aircraft configuration, size, weight, and performance parameters [18]. As shown in Figure 3, the conceptual design phase is a highly iterative process. It may be observed that, at all stages of the conceptual design phase, the designer must constantly check back to make sure that the aircraft design thus far has met all the requirements set at the beginning. The concept sketches are followed by an initial sizing of the aircraft. Here, the initial weight estimation for the conceptual aircraft is done in order to determine the maximum take-off weight for the specific mission requirements. The maximum take-off weight estimation would then be used to size the aircraft structure, wings, etc. Performance parameters, like thrust, take-off and landing runway length, landing gear requirements, are all based on the weight estimations and are designed to meet the regulations. Once a thorough weight analysis is carried out, the aerodynamics of the aircraft is investigated. Here, the aerofoil analysis and selection is done as well as an investigation into the wing configuration of the aircraft. The initial analysis is followed by the optimisation of aircraft sizing and performance parameters and are analysed in an iterative process until a conceptual aircraft with the required performance parameters are achieved [18].

The hypersonic transport vehicle to be designed must meet the following performance specifications:

1. The aircraft must accommodate at least 100 passengers;

2. It must be capable to take off and land onto current airports and runways;

3. Capable of cruising at an altitude of $30 \mathrm{~km}(100,000 \mathrm{ft})$ and at a speed of Mach 8; and

4. Must have a range of more than $12,000 \mathrm{~km}$.

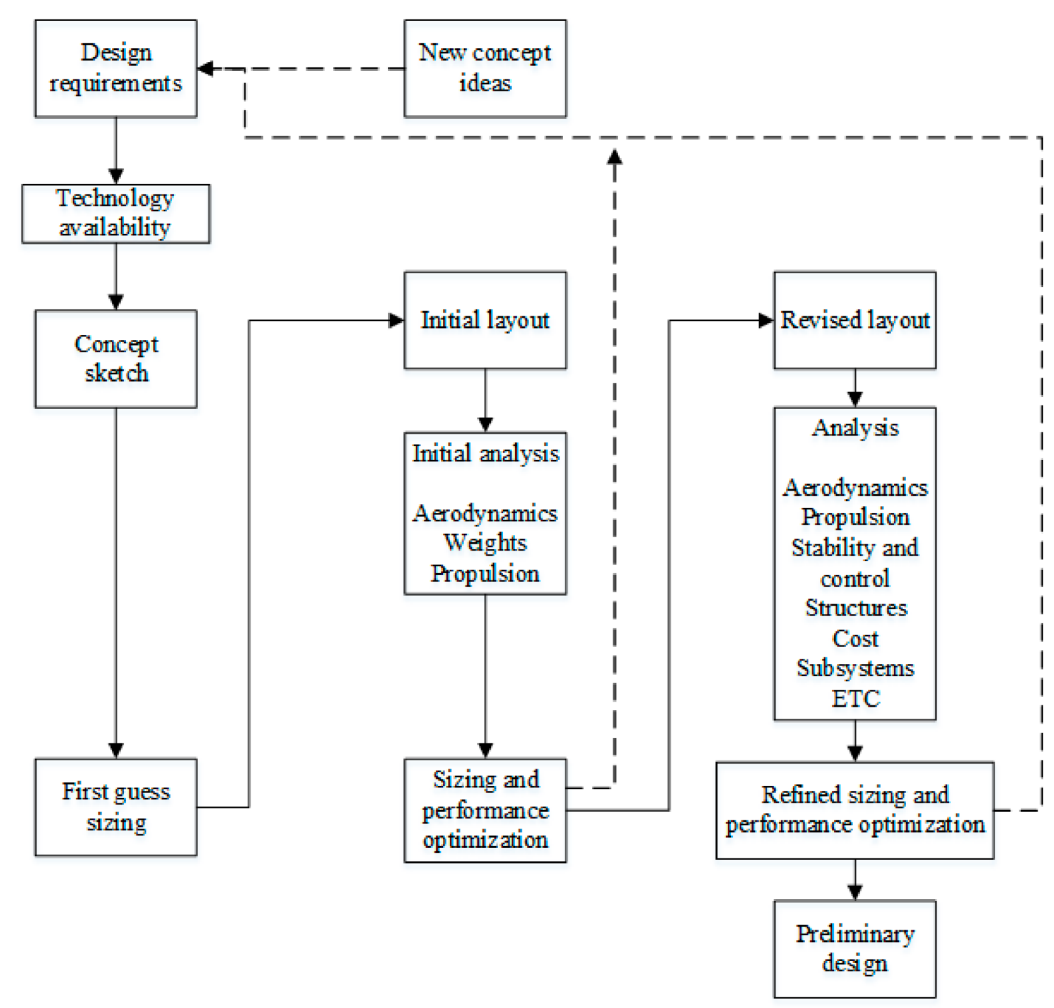

Figure 3. Aircraft conceptual design process. 


\section{Results and Discussion}

\subsection{General Aircraft Design}

A basic QFD (quality function deployment) analysis was employed to identify the important design factors (Figure 4). Through the QFD analysis, the material temperature resistance, drag, and weight were found to be the major design factors. This is justifiable as one of the most important issues to address in hypersonic flight is the excessive temperature rise. The drag is what is causing the surface temperature to rise and is, therefore, the second most important criteria.

This was followed by House of Quality (HoQ) analysis (Figure 5). Material temperature resistance, thrust and efficiency were identified as the major design requirements. This suggest that the use of latest material technologies, new composite materials and latest propulsion advancements play an important role in designing an aircraft that is both fuel efficient and cost effective. Advancements in aerodynamic design also plays an important role as suggested by the HoQ matrix. Reducing the drag of an aircraft even at a slight scale will reduce the fuel consumption significantly leading to low DOC. Collectively, these design features on a hypersonic transport vehicle means the difference between the aircraft becoming commercially successful or not.

\begin{tabular}{|c|c|c|c|c|c|c|c|c|c|c|c|c|c|}
\hline $\begin{array}{l}\text { 1= Equally } \\
\text { important } \\
\text { 3= More important } \\
\text { 9= Much more } \\
\text { important }\end{array}$ & $\begin{array}{l}\overrightarrow{5} \\
\frac{50}{20} \\
3\end{array}$ & $\stackrel{\infty}{\Xi}$ & 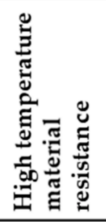 & 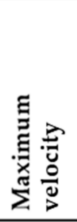 & 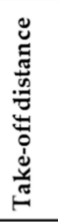 & 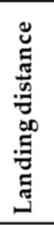 & 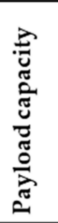 & 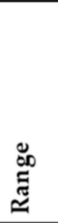 & 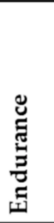 & 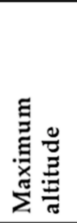 & के & 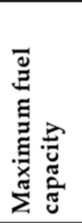 & స్ \\
\hline Weight & - & 1 & $1 / 9$ & 3 & 3 & 3 & 1 & 9 & 1 & 9 & 3 & $1 / 3$ & 33.44 \\
\hline Drag & 1 & - & 1 & 3 & 9 & 9 & 3 & 3 & 3 & 9 & 3 & 3 & 47.00 \\
\hline $\begin{array}{l}\text { High temperature } \\
\text { material resistance }\end{array}$ & 9 & 1 & - & 9 & 9 & 9 & 9 & 9 & 9 & 9 & 3 & 3 & 79.00 \\
\hline Maximum velocity & $1 / 3$ & $1 / 3$ & $1 / 9$ & - & 1 & 1 & $1 / 3$ & $1 / 3$ & $1 / 3$ & 1 & $1 / 3$ & $1 / 3$ & 5.44 \\
\hline Take-off distance & $1 / 3$ & $1 / 9$ & $1 / 9$ & 1 & - & 1 & 1 & 1 & 1 & 3 & 3 & 1 & 12.56 \\
\hline Landing distance & $1 / 3$ & $1 / 9$ & $1 / 9$ & 1 & 1 & - & 1 & 1 & 1 & 3 & 3 & 1 & 12.56 \\
\hline Payload capacity & 1 & $1 / 3$ & $1 / 9$ & 3 & 1 & 1 & - & 1 & 1 & 3 & 3 & 1 & 15.44 \\
\hline Range & $1 / 9$ & $1 / 3$ & $1 / 9$ & 3 & 1 & 1 & 1 & - & 3 & 3 & 3 & 3 & 18.56 \\
\hline Endurance & 1 & $1 / 3$ & $1 / 9$ & 3 & 1 & 1 & 1 & $1 / 3$ & - & 3 & 3 & 1 & 14.78 \\
\hline Maximum altitude & $1 / 9$ & $1 / 9$ & $1 / 9$ & 1 & $1 / 3$ & $1 / 3$ & $1 / 3$ & $1 / 3$ & $1 / 3$ & - & $1 / 3$ & $1 / 3$ & 3.67 \\
\hline Cost & $1 / 3$ & $1 / 3$ & $1 / 3$ & 3 & $1 / 3$ & $1 / 3$ & $1 / 3$ & $1 / 3$ & $1 / 3$ & 3 & - & $1 / 3$ & 9.00 \\
\hline $\begin{array}{l}\text { Maximum fuel } \\
\text { capacity }\end{array}$ & 3 & $1 / 3$ & $1 / 3$ & 3 & 1 & 1 & 1 & $1 / 3$ & 1 & 3 & 3 & - & 17.00 \\
\hline
\end{tabular}

Figure 4. Interrelationship analysis for QFD. 


$\begin{aligned} & \text { Correlation matrix legend } \\ & \text { Strong positive ++ } \\ & \text { Positive + } \\ & \begin{array}{l}\text { None } \\ \text { Negative- }\end{array} \\ & \text { Strongnegative - }\end{aligned}$

Figure 5. House of Quality analysis.

\subsection{Concept Generation}

Based on the above analysis five different sketches were generated.

\subsubsection{Concept 1}

The Figure 6a below shows the sketch of the first concept. It utilises a straight delta wing starting from half way along the fuselage with six control surfaces at the trailing edge. The aircraft has a large body for payload capabilities as well as a relatively large blunt nose for sufficient heat dissipation that is required at hypersonic cruise. The combined cycle engine intended for hypersonic travel would be located at the bottom of the fuselage to utilise the whole aircraft in the engine performance.

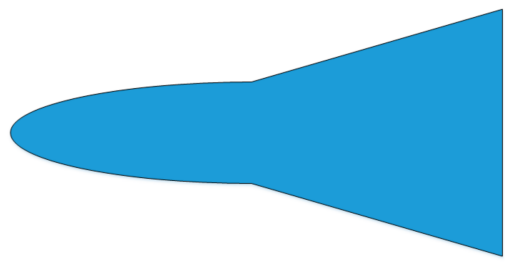

(a)

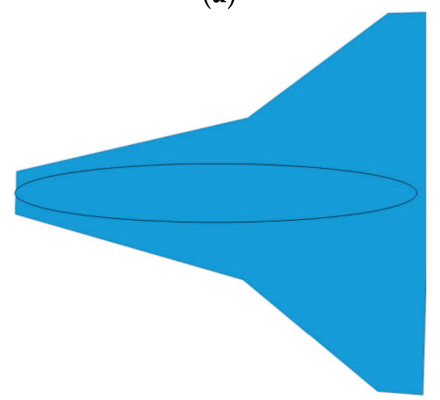

(c)

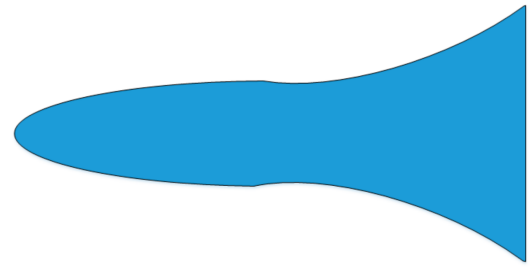

(b)

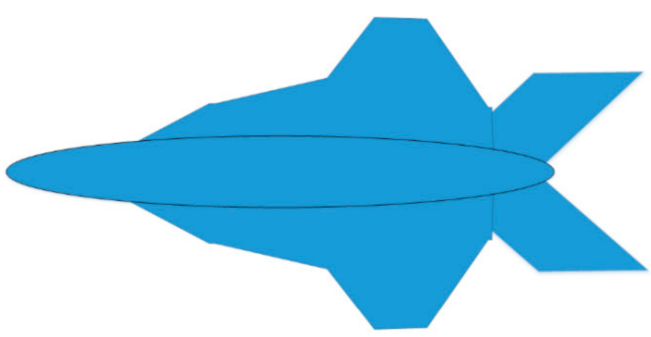

(d)

Figure 6. Cont. 


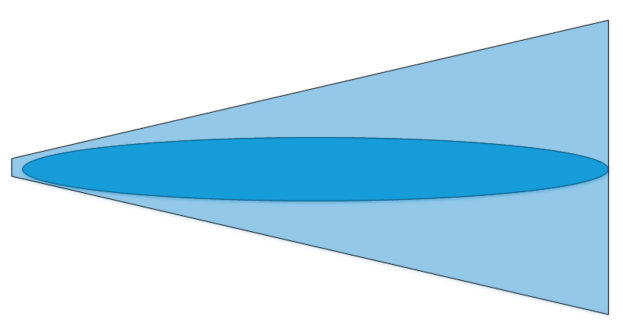

(e)

Figure 6. Concept sketches. (a) Concept 1; (b) Concept 2; (c) Concept 3; (d) Concept 4; (e) Concept 5.

\subsubsection{Concept 2}

The second concept shown above is in some ways similar to the first concept (Figure 6b). It utilises the whole aircraft for engine performance and has the wing towards the rear of the aircraft. The wing however has a ogival delta planform and has the possibility to be made larger to have a larger surface area as long as it remains within the Mach cone at the intended cruise speeds. The fuselage of the aircraft is intended to have a Sears-Hack body. The Sears-Haack body is a shape that has the lowest theoretical wave drag in supersonic flow for a specific body length and volume [19]. It was chosen to minimise wave drag during the supersonic flight segment and potentially reduce sonic boom intensity. This could have many advantages from better control in the transonic region to reduced noise levels while flying at transonic to supersonic speeds. On the other hand, the body will provide good amount of surface for heat dissipation during hypersonic speeds when the number one problem is the heat generated.

\subsubsection{Concept 3}

Concept three was designed considering the high temperatures at hypersonic speeds (Figure 6c). A large blunt nose is provided to evenly dissipate the heat and to keep it under control. The fuselage would also be blended in with the wing almost like a flying wing design. There are two vertical stabilisers on the wing tips to reduce the size of the stabiliser structure to make sure it remained within the Mach cone at cruise. The wind planform would be of a double delta type. The double delta is when the inner part of the wing has a very high sweepback while the outer part has less sweepback. This creates a high-lift vortex in a more controlled fashion and reduces the lift induced drag. There will, however, be two shockwaves generated beyond Mach 1 and would interact with each other. This could affect lift, as well as drag, and should be monitored closely should this design be picked for further investigation.

\subsubsection{Concept 4}

Concept four was designed with the intension of utilising expansion fans to speed the flow up over part of the wing to recover from the loss in speed when the flow encounters the shockwave originating from the nose (Figure $6 \mathrm{~d}$ ). The V-tail was chosen as a stabiliser as it acts as a vertical and horizontal stabiliser and is not as tall compared to a conventional vertical stabiliser. This would be advantageous as it would make it easier to keep all surfaces within the Mach cone at cruise speeds.

\subsubsection{Concept 5}

Finally, Concept 5 was designed with the intention of finding a balance between temperature control, minimal drag, and minimal structural complexity (Figure 6e). A simple straight delta would provide sufficient surface area to provide enough lift at subsonic speeds whereas the high sweep angle would minimise drag at high Mach numbers. A slightly blunted nose was chosen to balance between the surface area required to dissipate the heat generated and minimise the drag. A Sears-Hack body was also chosen for concept five fuselage to provide the same effects as described in the second concept. 
Once a number of concept ideas were generated, it was crucial to rank them against each other on the criteria's set in the QFD analysis that was undertaken. The decision matrix is shown in Figure 7. The first column in the figure shows the criteria followed by its weighing on the second column. Concept one was selected to be the bench mark for all the other concepts. A score, out of five, was given to each concept on a specific criterion that was multiplied by the criteria weighing. For example, looking at concept two efficiency, a score of five was given as it was deemed more efficient compared to concept one simply because it had a smaller body that could cause less drag. The two best ideas were chosen to be investigated and analysed further. This was done to ensure an understanding into how different wing planforms affected the performance of an aircraft as the rest of the aircraft design was in some ways similar. The two concepts selected for further analysis was Concept 3 and Concept 5 .

\subsection{Initial Weight Estimation}

The initial weight estimation of the conceptual aircraft was done using specialist aircraft analysis software called Advanced Aircraft Analysis (DARcorporation, Lawrence, KS, USA). The iterative process taken to appropriately estimate the take-off weight of the conceptual aircraft is detailed in this section.

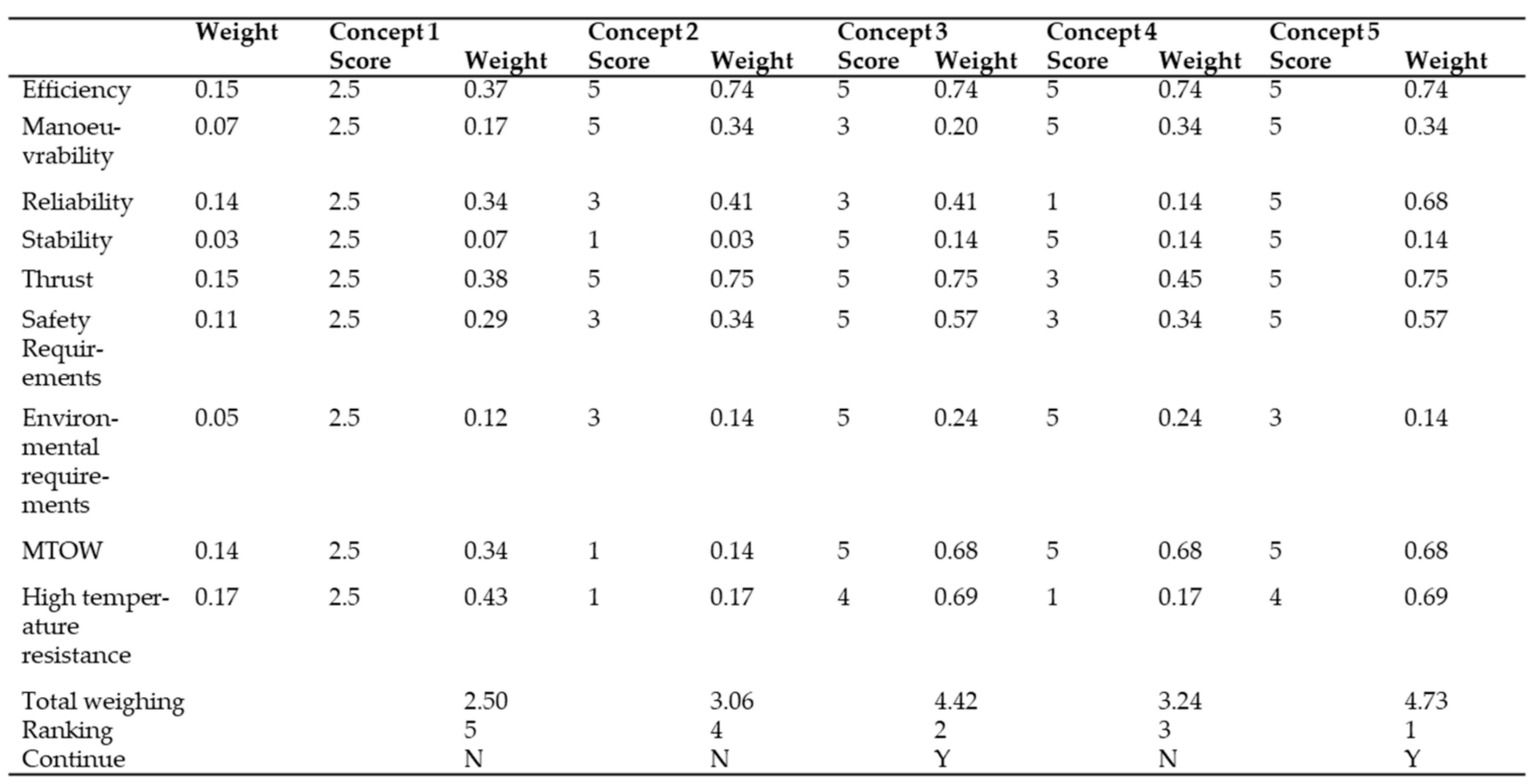

Figure 7. Concept decision matrix.

\subsubsection{Fuel Fractions}

The first step in calculating the estimated take-off weight of a conceptual aircraft is to estimate the amount of fuel required for the mission. To estimate the amount of fuel required, it was necessary to form a simple mission profile and divide it into simple flight segments. The warmup, taxi, and take-off flight segment fuel fractions were based on suggested fuel fractions that take into account fuel fractions of aircraft that adhere to the FAR 25 requirements. The climb segment fuel fractions however were calculated using AAA. The climb rate used to calculate the fuel fraction was set to $10 \mathrm{~m} / \mathrm{s}$ using a continuous climb approach to climb to the cruise altitude of $30 \mathrm{Km}$. This means the aircraft has $50 \mathrm{~min}$ to climb to its cruise altitude. The cruise segment mission fuel fraction was calculated for a $12,000 \mathrm{Km}$ range. This was done to ensure the aircraft met the requirements. It should also be noted that the $12,000 \mathrm{Km}$ range is only for the cruise segment of the mission and not for the entire mission. The flight segments and their corresponding fuel fractions obtained through the initial weight sizing module are shown in Table 4 below. 
Table 4. Mission fuel fractions.

\begin{tabular}{cc}
\hline \multicolumn{2}{c}{ Mission Fuel Fractions } \\
\hline Mission profile & $\mathrm{M}_{\mathrm{ff}}$ \\
Warm up & 0.9900 \\
Taxi & 0.9950 \\
Take-Off & 0.9950 \\
Climb & 0.8119 \\
Cruise & 0.6538 \\
Descent & 0.9850 \\
Land/Taxi & 0.9920 \\
\hline
\end{tabular}

Additionally, only one descent flight segment was added to the mission profile. This was based on the current regulations and the direction the commercial aviation requirements are heading with noise and noise reduction. More and more airports are expecting all aircraft to use a continuous descent procedure. With this procedure, the aircraft has lower power settings from higher altitude and has no level-off segments. Cutting out the stepping procedures significantly reduces noise levels and fuel consumption aiding in the mission becoming more commercially viable. Additionally, a typical mission fuel reserve of $5 \%$ was also assumed within the fuel weight calculations.

\subsubsection{Take-Off Weight Estimation}

Once the mission fuel fractions were completed, the take-off weight estimation was performed. Using this module, a regression line plot was obtained using regression line constants for supersonic cruise aircraft. The two constants, A (0.4221) and B (0.9876), which the weights module used along with data generated in the mission profile section (fuel fractions) were used to calculate the initial weight estimation of the conceptual aircraft. No data was available for hypersonic cruise flight as there have not been significant improvements that have been made in hypersonic transport vehicles, and the few studies and advancements that have been made are mostly conceptual and/or are not published. Therefore, supersonic cruise values were the closest to low hypersonic cruise that could be used in the initial weight estimation. The Figure 8 below shows the regression line plot created using aircraft empty $\left(\mathrm{W}_{\mathrm{E}}\right)$ and maximum take-off $\left(\mathrm{W}_{\mathrm{TO}}\right)$ weights. This was then used to find the coincident point between the regression line and the conceptual aircraft design line for a physical value relating to the empty and take-off weights. The conceptual aircraft weight estimation is shown on the plot as 'Design point'.

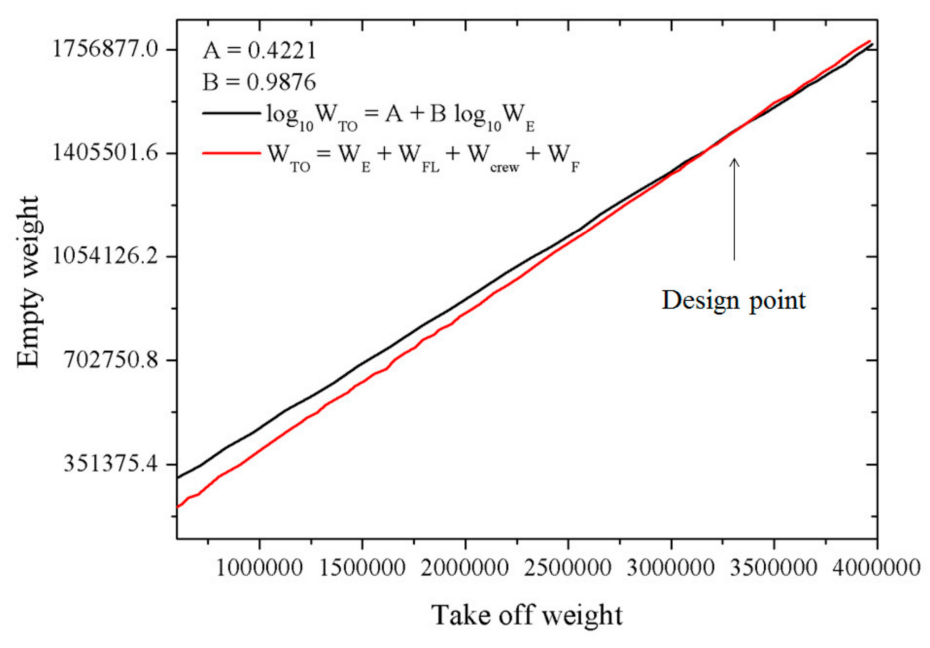

Figure 8. Design point plot. 
The empty weight of the conceptual aircraft was worked out to be 1,461,009 N, whereas the maximum take-off weight was 3,298,745 N. It can be seen from Figure 8 that the conceptual aircrafts weight estimation is in the upper end of the take-off weight suggesting it is heavier compared to typical aircraft that fly at supersonic speeds. This is justifiable as the conceptual aircraft is intended for the hypersonic cruise speeds and would require more structural integrity to withstand the loads, the temperatures, and the amount of fuel required to complete the mission specified.

Once an initial weight estimate was done, a more detailed breakdown of the weights list for the aircraft was obtained. Weight fractions from three different hypersonic aircraft by NASA that was in the AAA database were selected and an average weight fraction based on these aircrafts for each component of the aircraft was worked out. These fractions were then used to obtain individual component weights for the conceptual aircraft. Table 5 below shows a breakdown of the weight of each component on the aircraft including the weight fractions for those sections. It can be seen from the table that the components that has the highest weight fraction are the structure and the wing. This is due to the structural and thermal loads encountered during hypersonic cruise.

Table 5. Weights of individual components.

\begin{tabular}{ccccc}
\hline Component & $\mathbf{F}_{\mathbf{w}}$ & $\mathbf{W}_{\text {estimate }} \mathbf{~}$ & $\mathbf{\Delta W} \mathbf{~ N}$ & Weight $\mathbf{~}$ \\
\hline Fuselage & 0.077 & $234,987.0$ & 4030.8 & $239,017.8$ \\
Wing & 0.109 & $333,661.2$ & 5723.3 & $339,384.5$ \\
Empennage & 0.011 & $34,586.8$ & 593.3 & $35,180.1$ \\
Landing gear & 0.037 & $113,933.1$ & 1954.3 & $115,887.4$ \\
Nacelle & 0.019 & $56,966.5$ & 977.2 & $57,943.7$ \\
Structure & 0.253 & $774,134.6$ & $13,278.9$ & $787,413.5$ \\
Power plant & 0.123 & $375,368.8$ & 6438.8 & $381,807.6$ \\
Fixed Equipment & 0.094 & $286,867.2$ & 4920.7 & $291,787.9$ \\
Empty Weight & 0.470 & $1,436,370.7$ & $24,638.3$ & $1,461,009.0$ \\
\hline
\end{tabular}

Once the take-off weight was calculated an estimate of approximate ranges at different passenger load capacities was obtained (Figure 9). It may be noted that the point labelled 'design point' assumes 125 passengers with their standard luggage allowance (based on current allowance by airlines) and a typical flight crew with three pilots. Using these assumptions, the estimated range of the conceptual aircraft is found to be approximately $12,000 \mathrm{Km}$ and, thus, satisfies the requirements set earlier.

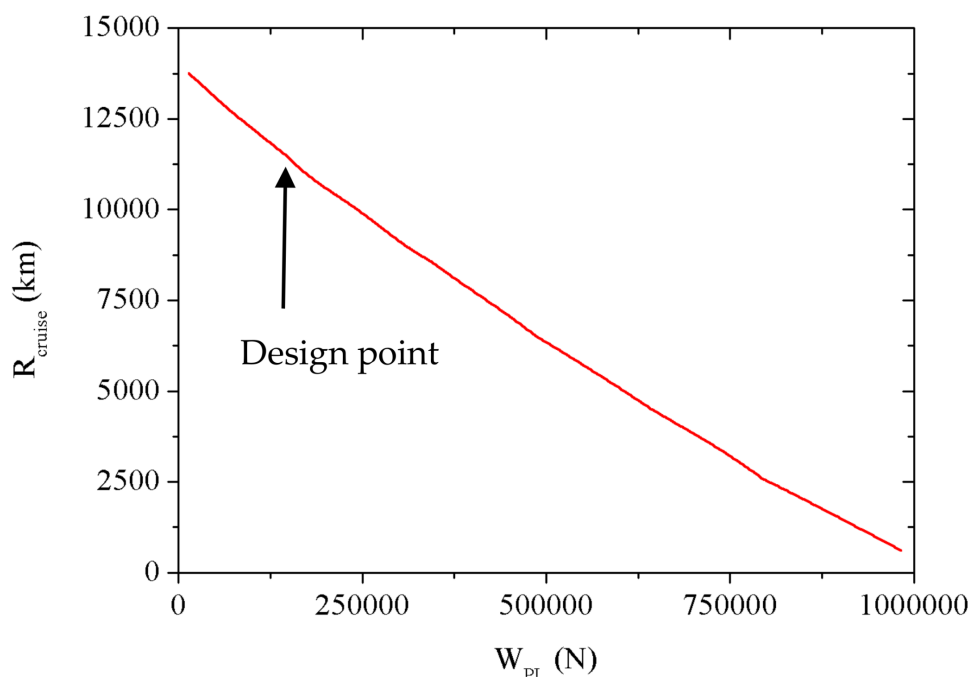

Figure 9. Cruise range vs. payload. 


\subsection{Aircraft Design II}

Once an estimated take-off weight was obtained for the conceptual aircraft, the selected concept ideas were designed and modelled using Solidworks and further analysed using Ansys Fluent. This section details the iterative process undertaken to analyse and compare the conceptual aircraft design.

\subsubsection{Aerodynamics}

\section{Airfoil}

The first step in designing and analysing the aerodynamics of an aircraft is to ensure the aerofoil that is going to be used is chosen in order to know the lifting properties of the aerofoil and aid in the sizing of the aircraft. For the aerofoil analyses, a supercritical aerofoil designed by NASA (Figure 10a), bespoke supercritical aerofoil based on the NASA aerofoil (Figure 10b) and a simple wedge aerofoil with $1 \%$ thickness to chord ratio (Figure 10c) were investigated. The aerofoil profiles for the three aerofoils chosen are shown in the Figure 10.

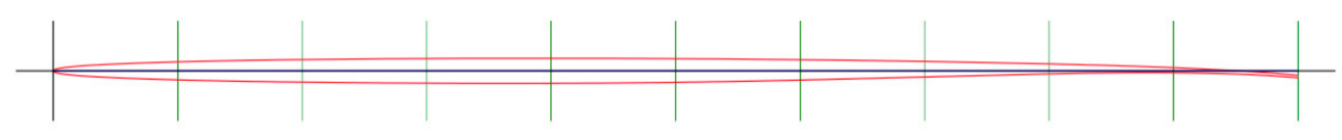

(a)

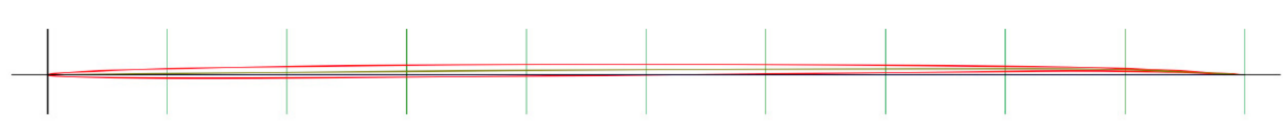

(b)

(c)

Figure 10. (a) NASA sc(2)-0402 supercritical aerofoil; (b) NACA 0801 bespoke generated supercritical aerofoil; and (c) wedge aerofoil ( $1 \%$ thickness to chord ratio).

Supercritical aerofoils are known for their properties of delaying the onset wave drag in the transonic speed range. They have a flattened upper surface and a cambered aft section along with a larger leading edge radius compared to NACA (National Advisory Committee for Aeronautics) six-digit laminar aerofoil shapes [20]. As the aircraft enters the transonic speed region, the air accelerating around the upper surface of the wing approaches and reaches Mach 1 . This causes shockwaves to form on the wing hence causing wave drag. More importantly, the shockwave causes the flow behind it to separate, destroying lift and weakening the effectiveness of the control surfaces at the trailing edge, thus affecting the control and stability of the aircraft. The supersonic flow over a supercritical aerofoil terminates in a weaker shock, thereby postponing the shock-induced boundary layer separation and temporary loss of aircraft control.

The aerofoils were analysed using Ansys Fluent at different angle of attacks and flow speeds. Analysis was also carried out on the NASA sc20402-il aerofoil for validation purposes. The computational results were compared with data obtained from open literature. It was observed that the results obtained had an error of $0.34 \%$ which is deemed to be accurate. The results for the NASA sc20402-il aerofoil shown in the figures below are from literature [21]. The results obtained are shown in Figures 11-13. 


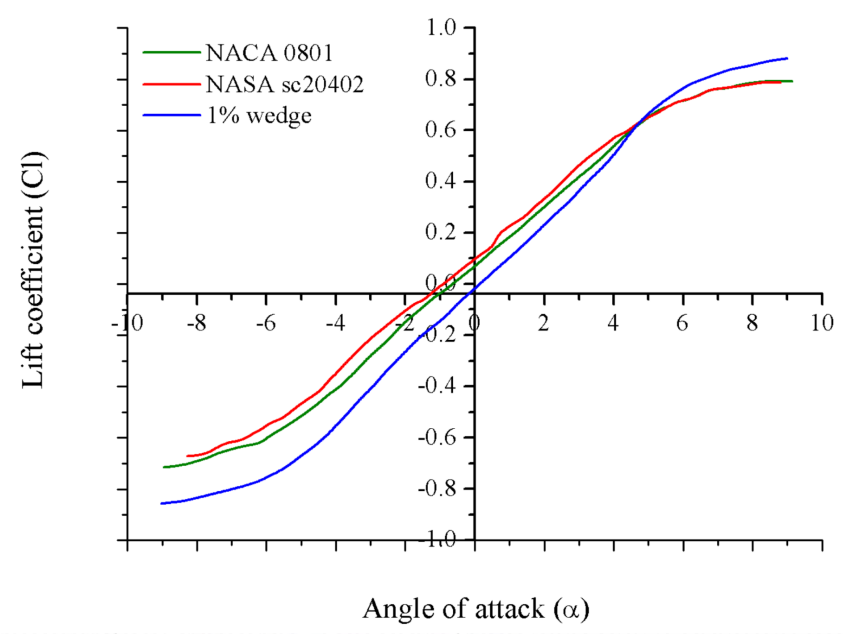

Figure 11. Lift coefficient vs. angle of attack.

In Figure 11 it may be noted that the wedge aerofoil does not generate as much lift at low angles of attack, but slightly higher at angles of attack of six degrees and above. The supercritical aerofoils, however, produce more lift at lower angles. This is expected, as separation is less likely to occur at lower angles compared to higher angles. The maximum lift coefficient for the supercritical aerofoils were found to be 0.8 .

Figure 12 shows the drag coefficient $\left(C_{d}\right)$ vs. the angle of attack. The drag on the NASA sc20402-il aerofoil is higher compared to the bespoke NACA 0801 supercritical and the single wedge aerofoil at low angles but are slightly lower at higher angle of attacks. This is due to the NASA sc20402-il aerofoil having a thickness to chord ratio of $2 \%$ compared to the other two aerofoils having $1 \%$ thickness to chord ratios.

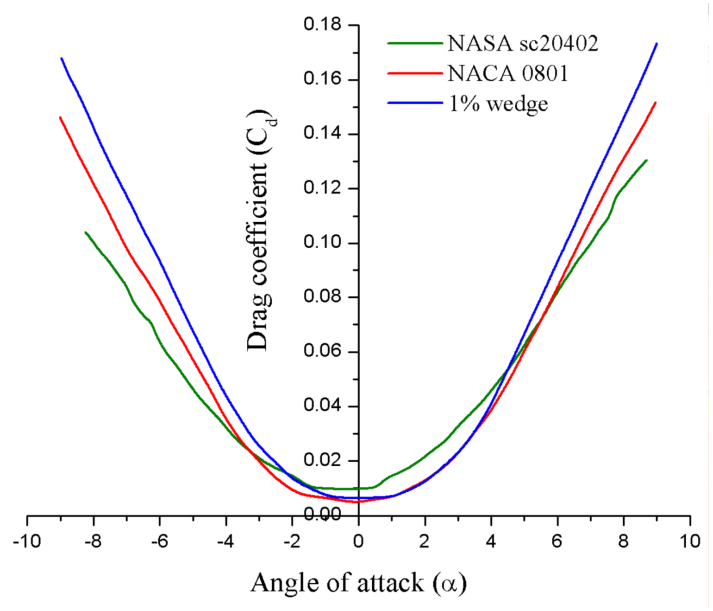

Figure 12. $C_{d}$ vs. angle of attack.

Figure 13 below, is a comparison of the aerofoil lift to drag ratios plotted against angle of attack. It becomes evident that the supercritical aerofoils by far have better lift to drag ratio values compared to the wedge aerofoil. This is crucial in aircraft design as enough lift is required for the aircraft to take-off with minimal drag. Observing both supercritical aerofoils, a reduction in thickness to chord ratio on the bespoke NACA 0801 aerofoil of $1 \%$ increases the maximum lift to drag ratio by almost two-fold. Although a higher lift to drag ratios were obtained for the supercritical aerofoils, it is known that wedge aerofoils do perform better in supersonic and hypersonic conditions. This is achieved by preventing the formation of detached bow shocks in front of the aerofoil. In comparison to subsonic aerofoils, 
the large round leading edge on a subsonic aerofoil that is incorporated to reduce flow separation over a large range of angles of attack, would act as a blunt body in supersonic and hypersonic conditions. The bow shock generated as a result of the blunt body effect of the leading edge will significantly increase the wave drag.

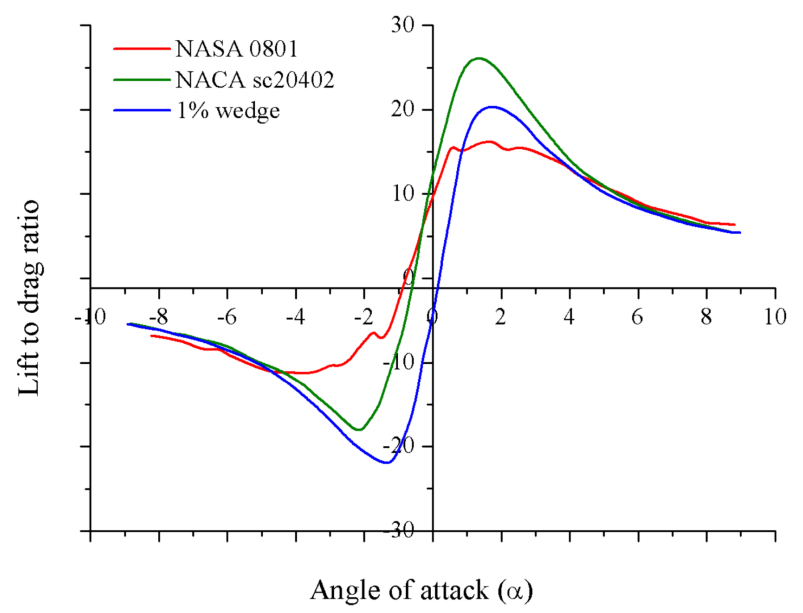

Figure 13. $C_{I} / C_{d}$ vs. angle of attack.

Aircraft that use wedge aerofoils must use enough high lift devices to increase lift at lower speeds. However, this significantly increases the structural complexity of the wing. Therefore, it was decided to further analyse the NACA 0801 supercritical aerofoil at higher Mach numbers to see whether the leading edge behaves as a blunt body in supersonic and hypersonic flows. Figures 14 and 15 show results obtained through Mach contour plots of the NACA 0801 supercritical aerofoil at speeds of Mach 2 and Mach 7. It was observed that due to the thickness to chord ratio of the aerofoil being significantly low $(1 \%)$ compared to conventional aerofoils, the effects are not as significant as ordinary subsonic aerofoils. It was found that through the use of very thin aerofoils, although not as good as wedge aerofoils, better lift coefficients are achieved at lower speeds with improved performance at supersonic and hypersonic speeds compared to conventional aerofoils.

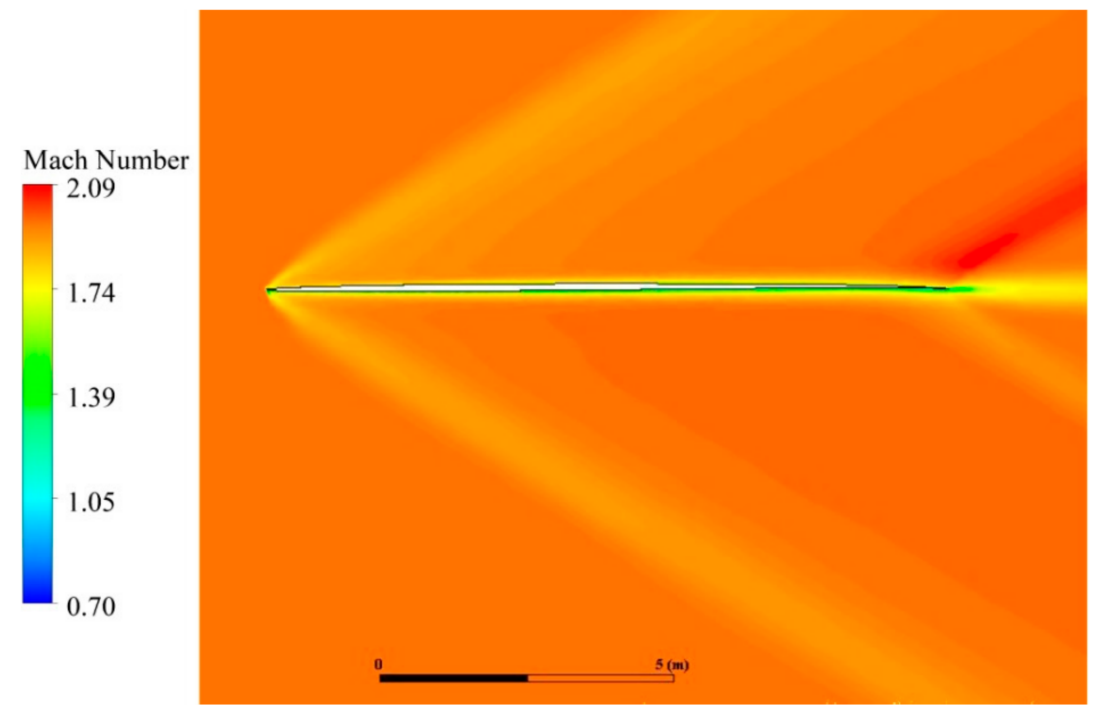

Figure 14. NACA 0801 aerofoil at Mach 2. 


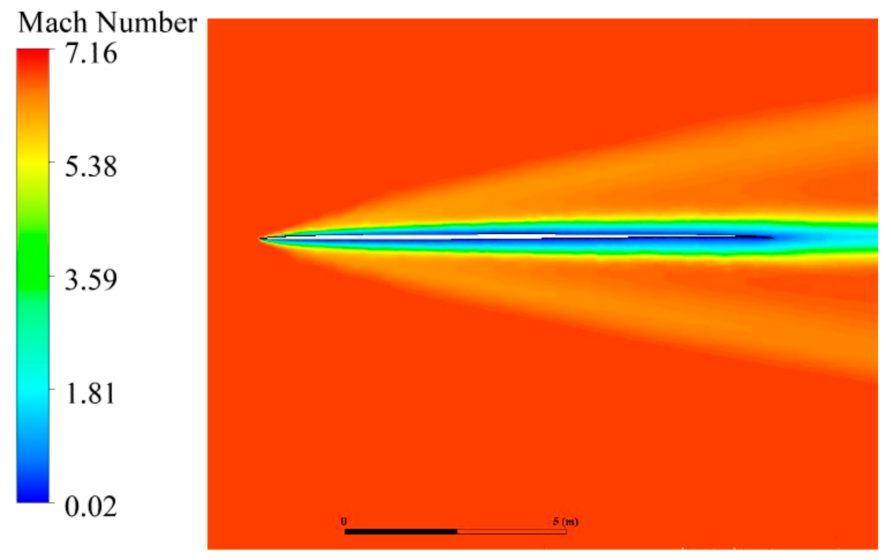

Figure 15. NACA 0801 aerofoil at Mach 7.

From the above figures, it is evident that the flow around the aerofoil is not significantly affected at low Mach numbers due to the thin geometry of the aerofoil. However, at higher Mach numbers as shown in Figure 15, the blunt body effects are visible. This can be observed around the aerofoil at Mach seven which is an indication of the boundary layer developments. The bespoke NACA 0801 supercritical aerofoil was chosen, as it had the highest lift to drag ratio and the lowest feasible thickness to chord ratio of $1 \%$.

\section{Fuselage and Wing Sizing}

As concept three and five were chosen to be investigated further, the fuselage profile needs to be designed. The Sears-Haack body was used as the fuselage and the major geometric parameters were determined. The fuselage is $90.72 \mathrm{~m}$ long and has a maximum radius of $4 \mathrm{~m}$ at the centre. The fuselage design was followed by the modelling of the vertical tail and the aircraft wing. Three different configurations, the double delta, straight delta, and the ogival delta, were investigated (Figure 16). The ogival delta configuration was analysed to study the effect of wing geometry on the drag at high speeds.

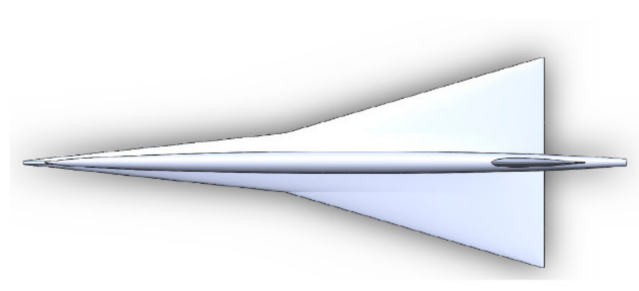

(a)

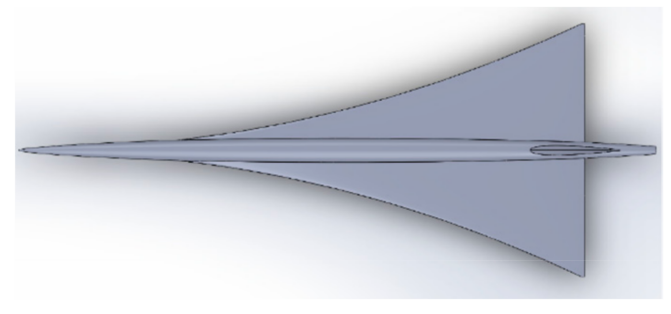

(b)

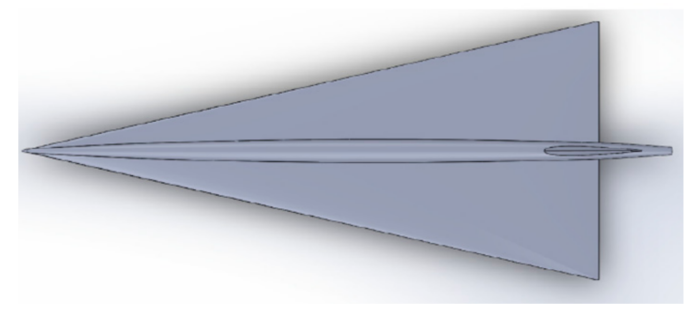

(c)

Figure 16. (a) Double delta configuration; (b) Ogival delta configuration; and (c) Straight delta configuration. 


\subsection{CFD Analysis of Different Wing Configurations}

After modelling the three aircraft configurations, 2-D and 3-D CFD analysis were performed. To understand the extent at which the configurations affect the drag coefficient at different flow regimes (subsonic, transonic, supersonic, and hypersonic), a full size 3-D CFD analysis was done for each configuration initially. It was observed that the ogival delta and the straight delta configurations had a 'nose cone' where the intention for it was to reduce the drag on the aircraft and provide a body that was blunted enough to aid in temperature management. To analyse the effect of the wing configuration better while at the same time to analyse the effect of the 'nose cone', it was decided to make a configuration of the double delta aircraft with the only change being the addition of the 'nose cone'. The two geometries are shown in the Figure 17. The results were obtained and plotted and are shown in Figure 18. From this figure, it is evident that the 'nose cone' makes a significant difference on drag. The double delta configuration has the highest drag coefficient across all flight speeds with the largest increase in drag across the transonic region (0.8-1.2 Mach). With the addition of the nose cone, the drag on the same double delta configuration is significantly reduced. The nose cone also has a positive impact on the total increase in drag across the transonic region when compared to its counterpart with largely blunted nose. If the double delta configuration with the largely blunted nose is put to one side, the only difference between the other three aircrafts tested is the wing configurations. The ogival delta was found to have the highest drag compared to the double delta and the straight delta. Comparing the straight delta with the double delta, it can be seen that the straight delta performs better when drag is considered.

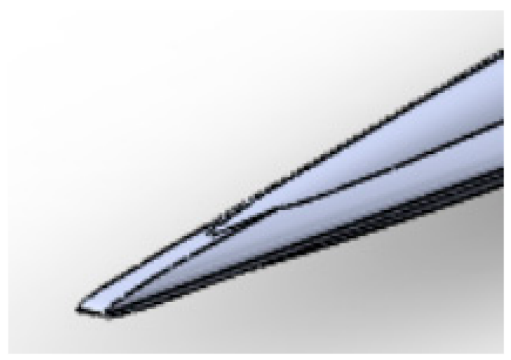

(a)

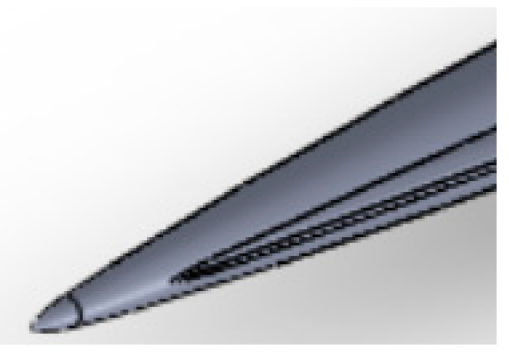

(b)

Figure 17. (a) Blunted nose; and (b) nose cone.

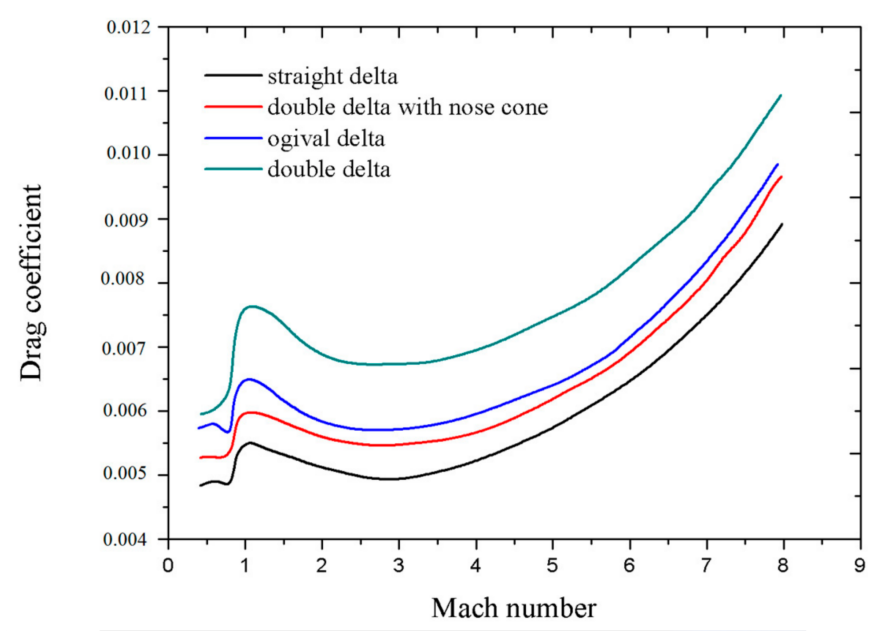

Figure 18. $C_{d}$ vs. Mach number for different wing configurations.

Based on the drag results obtained and due to the geometrical complexity of the ogival delta configuration, this was not used for further analysis. The double delta and the straight delta were 
further analysed with the aim of understanding the effects of different sweep angles on the leading delta. For this, the leading delta sweep angles were changed until the double delta configuration became a straight wing configuration. The results obtained are shown in Figure 19.

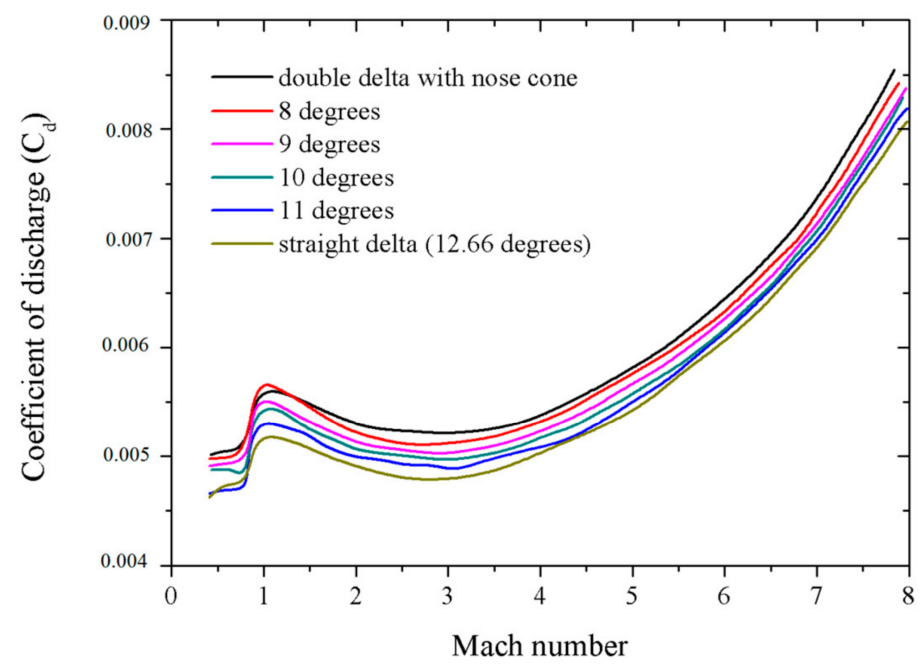

Figure 19. Drag coefficients for different leading delta sweep angles.

It may be noted that as the sweep angle of the leading delta is increased (meaning less sweep and moving towards a straight delta configuration), the drag coefficient is reduced. The configuration with the lowest drag coefficient is the straight delta configuration. One of the main contributors to a rise in drag is the sharp turning angle that is introduced when a different sweep angle is applied at the front. This causes a second shockwave to appear causing an increase in the overall drag on the aircraft. Figure 20a below shows a contour plot of the double delta configuration with the nose cone at a speed of Mach 2.

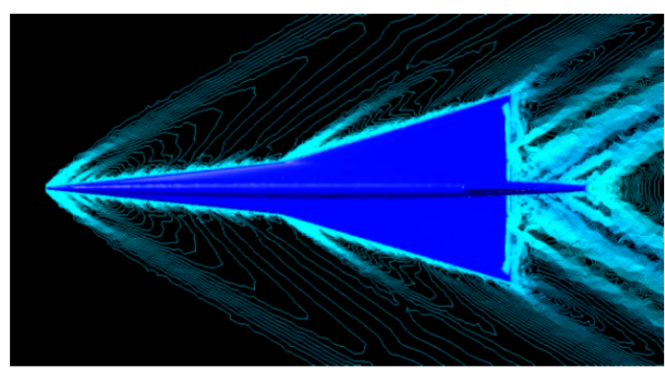

(a)

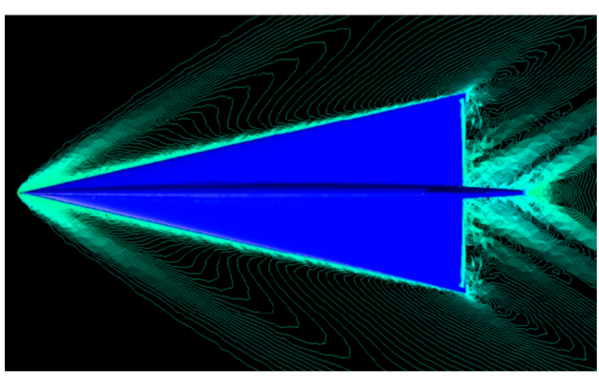

(b)

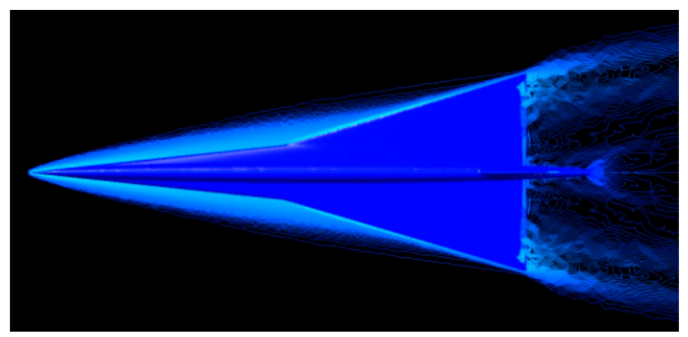

(c)

Figure 20. (a) Contour plot of the double delta-configured aircraft at Mach 2; (b) contour plot of the straight delta-configured aircraft at Mach 8; and (c) contour plot of the double delta-configured aircraft at Mach 8 . 
In the contour plot, the shockwaves are clearly visible at the nose and at the sharp turn on the leading edge of the double delta. There are also multiple shockwaves stemming from the trailing edge of the wing and the vertical stabiliser area. Conversely, Figure 20b shows the contour plot obtained for the straight delta configuration at a speed of Mach 2. Due to lower number of shocks on the straight delta configured aircraft, and the fact that the flow deflection angle remained the same due to the presence of the nose cone, the straight delta wing had a lower drag compared to the double delta wing.

The CFD analysis on the two configurations revealed that the double delta wing tips were outside of the Mach cone at Mach 8 and the shockwave was directly hitting the leading edge of the wing (Figure 20c). This is undesirable at hypersonic speeds as it causes heating problems. As the leading edge of the wing is designed to be very thin to avoid blunt body effects, there is not much material to absorb extreme heat loads. The shockwave hitting the leading edge would act like a very hot blowtorch, and would burn through the material. As discussed earlier, although the flow deflection angle on both wing configurations are the same due to the nose cone, the wing tips on the double delta remain outside the Mach cone at the required cruise speed of Mach 8 whereas the wing tips of the straight delta remain inside the Mach cone. This is because the wingspan on the double delta configuration is required to be longer compared to the straight delta to maintain the required wing surface area. This is also another significant factor contributing to an increase in drag. Subsequently, based on drag coefficient results and the shockwave and shock cone effects on the double delta configuration discussed above, it was decided to use the straight delta wing configuration. This would not only reduce the drag coefficient of the aircraft compared to the other configurations, but would also reduce the structural complexity of the aircraft, hence, reducing manufacturing costs.

\subsection{Final Conceptual Aircraft Design and Sizing}

After the long iterative process of aircraft design and analysis, the final clean aircraft concept was obtained (Figure 21). The parameters of the aircraft concept outlined in the Table 6 below are the result of an iterative process of general aircraft design knowledge [22].

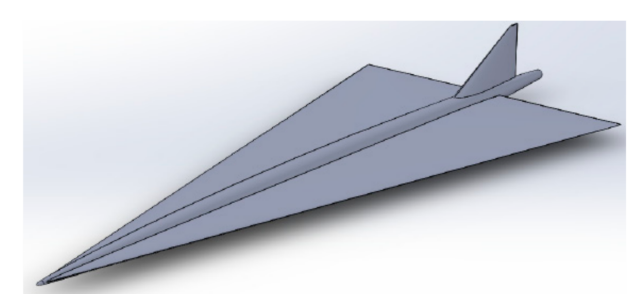

(a)

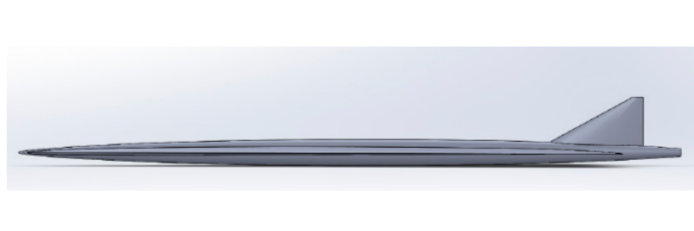

(b)

Figure 21. (a) Isometric view of the final straight delta wing aircraft concept; and (b) side view of the final straight delta wing aircraft concept.

Table 6. Design parameters of the final aircraft concept.

\begin{tabular}{cc}
\hline Wingspan & $35.52 \mathrm{~m}$ \\
Root chord & $80 \mathrm{~m}$ \\
Tip chord & $2 \mathrm{~m}$ \\
Mean aerodynamic chord distance (from nose) & $53.37 \mathrm{~m}$ \\
Taper ratio & 0.025 \\
Sweep angle of wing leading edge & 77.34 degrees \\
Wing wetted area & $1456.32 \mathrm{~m}^{2}$ \\
Aspect ratio & 0.87 \\
Vertical stabilizer surface area & $47.3 \mathrm{~m}^{2}$ \\
VS Root chord & $12.78 \mathrm{~m}$ \\
VS Tip chord & $1.5 \mathrm{~m}$ \\
VS Sweep angle & 61.7 degrees \\
Total aircraft length & $90.72 \mathrm{~m}$ \\
Aircraft nose flow deflection angle & 12.66 degrees \\
\hline
\end{tabular}




\subsubsection{Propulsion Integration and Final Aircraft Design Analysis}

Once a final conceptual aircraft design was done, this was integrated with the combined cycle engine. Multiple designs were generated and analysed to study its effect on the aircraft performance. Some of these were the engine location been too far ahead or back of the aircraft (affecting CG and stability), the entire engine with the forebody mounted too low to a point where it was remaining outside of the Mach cone even at low Mach numbers causing excessive drag. In addition to this, some designs had more impact on the engine performance. These affected the performance of the engine to the point where the engine was not producing enough thrust to maintain hypersonic cruise speeds. The final conceptual aircraft with the integrated combined cycle engine was achieved through an iterative process of the various designs (Figure 22).

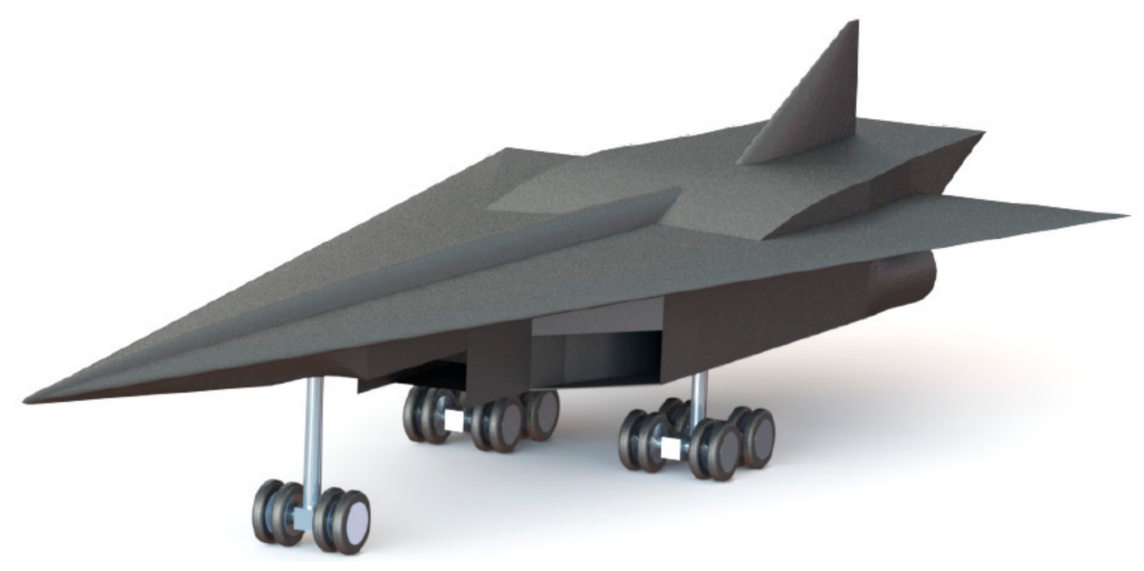

Figure 22. Final conceptual aircraft with the integrated engine.

\subsubsection{CFD Analysis of a Final Conceptual Aircraft with an Integrated Engine}

This section details the analysis undertaken on the final aircraft design achieved for an efficient hypersonic flight. Figure 23 shows the pressure contour plot of the aircraft at a speed of Mach 4 . This analysis was undertaken to have a better understanding of the aircraft performance at the transition speeds from which the aircraft will switch between the ramjets to the scramjet. The figure clearly portrays the shock train inside the scramjet.

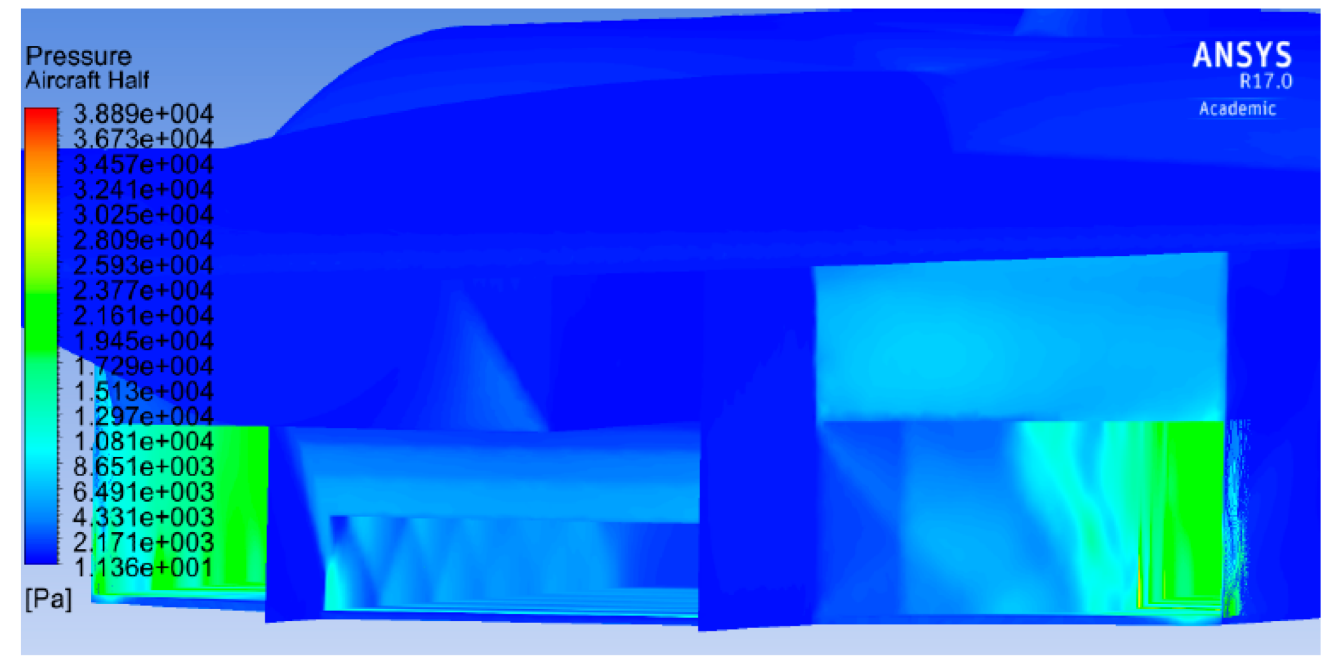

Figure 23. Shock train inside the scramjet at Mach 4 . 
Table 7 shows the comparison of the performance parameters for different flight conditions. The CFD analysis was performed for three different cases. The first case was an aircraft flying at Mach 4 and at an altitude of $25 \mathrm{~km}(80,000 \mathrm{ft})$, the second was for a flight speed of Mach 8 at an altitude of $30 \mathrm{~km}(100,000 \mathrm{ft})$ with the ramjets inlets open and the third case was for a flight speed of Mach 8 , altitude of $30 \mathrm{~km}(100,000 \mathrm{ft})$, with the ramjets sealed off.

Table 7. CFD results of aircraft integrated with engine.

\begin{tabular}{ccccccc}
\hline & Ramjet Sealed Off & Flight Speed & Cd & Cl & Cm & Drag Force \\
\hline Case 1 & No & Mach 4 & 0.05 & -0.0062 & 0.77 & 2.35 \\
Case 2 & No & Mach 8 & 0.057 & 0.00424 & -0.109 & 4.825 \\
Case 3 & Yes & Mach 8 & 0.032 & 0.015 & -0.63 & 2.71 \\
\hline
\end{tabular}

The drag, lift, and pitching moment coefficients on the aircraft at an angle of attack of zero degrees were analysed to understand the aircraft behaviour. Initially the performance of the Mach 4 aircraft (Case 1) was compared with the Mach 8 aircraft (Case 2). It may be observed that at the cruise speed of Mach 8 (Case 2), the drag had exponentially increased. One of the main contributors to this was the build-up of backpressures on the ramjets as they were not designed for hypersonic speeds. Additionally, the vertical stabiliser was moved higher to accommodate the nozzle of the scramjet which was mounted higher than the top surface of the wing and fuselage. This was done during the iterative design and analysis phase to ensure the inlets of the ram and scramjet engines were not affected by the aircraft shock cone. This increased the drag on the aircraft further.

Furthermore, the forebody of the aircraft was shaped to enhance the lifting properties of the aircraft, so in effect, would behave similar to a waverider aircraft. It can be seen from Figure 24 that the flow is now disturbed and the shockwaves generated due to this forebody geometry, would interact with the side of the ramjets.

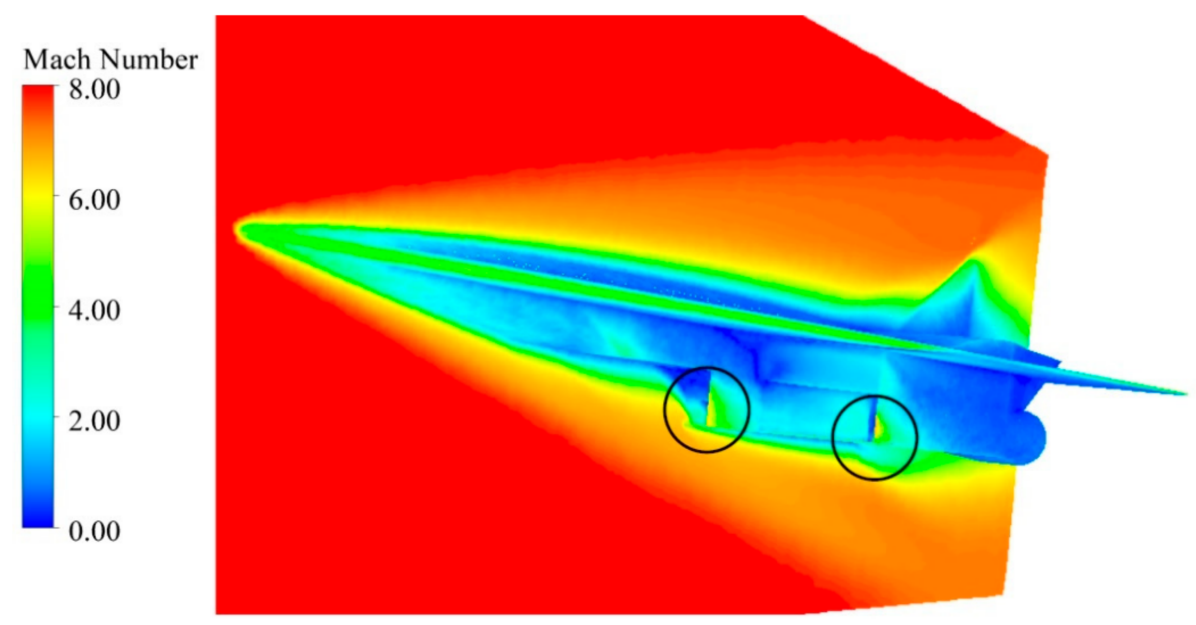

Figure 24. Mach number contour of the aircraft at Mach 8.

Case 3 involves a mechanism to seal off the ramjet engines once the scramjet was engaged. This was done to reduce the rise in drag due to increase in backpressures inside the ramjet and to make use of the disturbance of the flow due to the forebody to enhance the waverider effect of the aircraft to produce more lift. It can be seen that this resulted in an increase in lift coefficient and a reduction in the drag coefficient of the aircraft at Mach 8 (Table 7). The increase in lift was caused by the enhanced waverider effect on the aircraft body created when the ramjet is sealed off. This is portrayed by the density volume rendering in Figure 25. The presence of a lower density above the wings indicates the effects of the waverider geometry. The effective Mach cone of the aircraft is visible in this figure. 


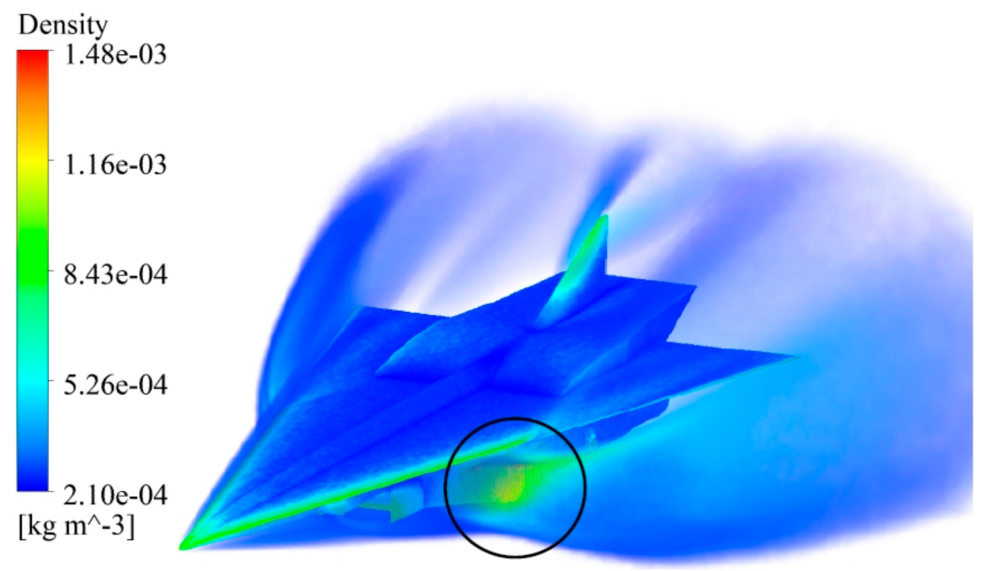

Figure 25. Density volume rendering of the aircraft with the ramjet sealed off.

Analysing the drag coefficients, the effect of sealing the ramjets at hypersonic speeds has a large impact on the drag (Table 7). The drag coefficient at Mach 8 with the ramjets sealed is lower than the drag coefficient at a flight speed of Mach 4 which is when the ramjet inlets are open. A similar trend is not observed for the drag force as its value is also dependent on the wing surface area $S$, and the density of air, $\varrho$, at flight altitude.

It may be noted that the lift coefficient increases as the flight speed increases to Mach 8 (Table 7). This is an indication of the limited waverider effect of the forebody geometry of the aircraft. The significant increase in the lift coefficient when the ramjets are sealed off is also a solid indication of the enhancement of the waverider geometry as discussed earlier. By sealing the ramjets, the lift has been improved by over $350 \%$ at hypersonic speeds.

Negative pitching moment coefficient is an indication of a nose down pitching moment whereas a positive coefficient correlates to a nose up pitching moment. At Mach 8, the aircraft is experiencing a nose down pitching moment. In addition to this, the effect of sealing the ramjets increases the nose down pitching moment on the aircraft. On the other hand, there is a nose up pitching moment induced on the aircraft at Mach 4. This is expected as the results obtained corresponds with the general behaviour of the aircraft with an integrated scramjet.

The increased nose down pitching moment experienced at Mach 8 when the ramjets are sealed is a clear indication of the performance improvement on the scramjet nozzle. As the flow through the ramjet nozzles are blocked off, there is no flow interaction between the scramjet and the ramjet nozzles, hence the scramjet nozzle performance in increased, higher pressures were achieved at the scramjet nozzle. This enhanced the nose down pitching moment on the aircraft. However, as these simulations were done under cold flow conditions and the combustion effects were not modelled, the pitching moments obtained are an underestimate and would greatly increase when combustion is applied. Nonetheless, this is still a good indication of the direction of the pitching moment experienced by the aircraft at cruise conditions.

\subsubsection{Basic Stability Analysis}

In the basic stability analysis the CG values of the aircraft was determined first. This was calculated based on the weight fractions of each component as well as the locations of each component relative to the nose of the aircraft $(X)$. The empty weight CG was found to be $45.81 \mathrm{~m}$ from the nose of the aircraft. Once the CG was obtained, the mean aerodynamic chord (MAC) of the wing was calculated by using the $M A C$ calculation formula shown in Equation (1):

$$
M A C=c_{r} \frac{2}{3}\left[\left(1+t+t^{2}\right) /(1+t)\right]
$$


The MAC location was found to be $53.37 \mathrm{~m}$ from the nose of the aircraft for a root chord of $80 \mathrm{~m}$ and taper ratio of 0.025 . This was followed by the calculation of the static margin of the aircraft. As the aircraft in the present study is a tailless aircraft where the aerodynamic centre coincides with the neutral point, the static margin was found by the formula:

$$
S M=\frac{M A C-X_{c g}}{M A C}
$$

The static margin was calculated to be $14.2 \%$ based on empty weight CG analysis of the aircraft which is deemed longitudinally stable. However, with the addition of fuel, it is anticipated that the CG will shift which will affect the static margin of the aircraft. Generally speaking, a nose down pitching moment is accepted as longitudinal stability, however, at supersonic speeds, it is expected that the aircraft will experience nose up pitching moments due to effects caused by the integrated combined cycle engine. To minimise the instability this causes on the aircraft, the trim settings must be correctly adjusted to control the nose up moments on the aircraft. To aid in the management of the moments at supersonic speeds, the CG of the aircraft with the payload could be placed further forward to increase the static margin of the aircraft at supersonic speeds. To achieve this, a basic aircraft configuration was done to position the fuel tanks and the passengers in the aircraft. A basic schematic of the layout is shown in Figure 26. The regions marked with red are where the fuel tanks would be placed and those with green will be where the passengers and cargo would be placed.

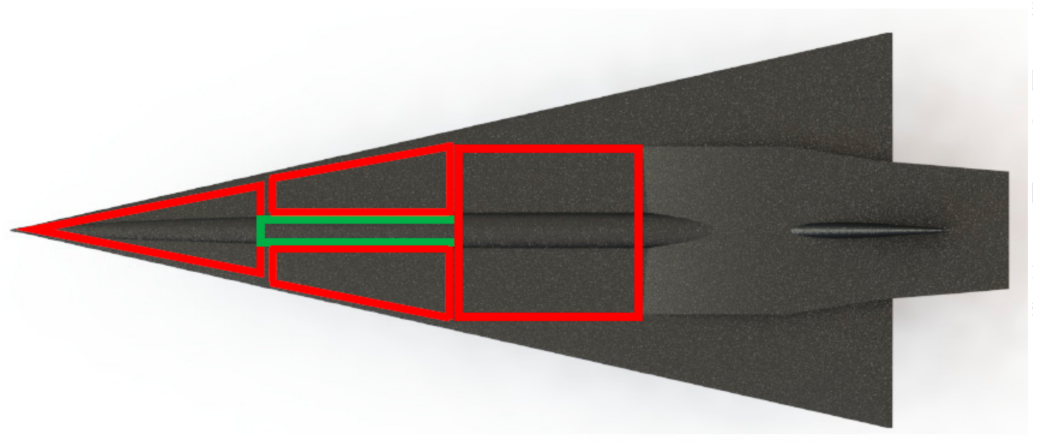

Figure 26. Concept aircraft layout of the fuel tanks and passenger cabin.

Using the locations of the fuel tank and the passengers and their equivalent weight, the CG value of the aircraft was found to be $41.27 \mathrm{~m}$ when it is fully loaded. The corresponding static margin was found to be $22.7 \%$.

As the aircraft burns fuel throughout the flight, the CG position would move back and, hence, reduce the static stability. However, although the CG shifts back, it will always remain in front of the aerodynamic centre of the aircraft maintaining stability. Furthermore, as the aircraft naturally has a nose down pitching moment at hypersonic speeds, the reduction in static stability as the fuel is used up does not necessarily imply the overall aircraft stability is reduced at hypersonic speeds. However, at approach and landing, CG control could be useful in controlling the static stability of the aircraft as desired. To achieve this, active fuel transfer can be applied on the aircraft to move the remainder of the fuel forward or aft of the aircraft and use it as ballast to adjust the CG, hence, changing the static margin to better suit the flight conditions.

\subsubsection{Landing Gear}

The landing gears (LG) were mounted in a tricycle configuration with the main two LG just behind the CG and a single nose gear mounted towards the front of the aircraft. The two main LG are in the same distance from the CG in the $x$ and $y$ directions in order to carry the same load. The nose gear is further away from the CG carrying less load. The share of the main gear and the nose gear 
has been calculated and positions of the LG set such that the main LG carries a maximum of $75 \%$ of the total static load. The nose gear would then carry a minimum of $25 \%$ of the static load which is optimum for tricycle configuration. A side view of the aircraft with the forward and aft CG locations as well as the LG locations with dimensions are shown in the Figure 27.

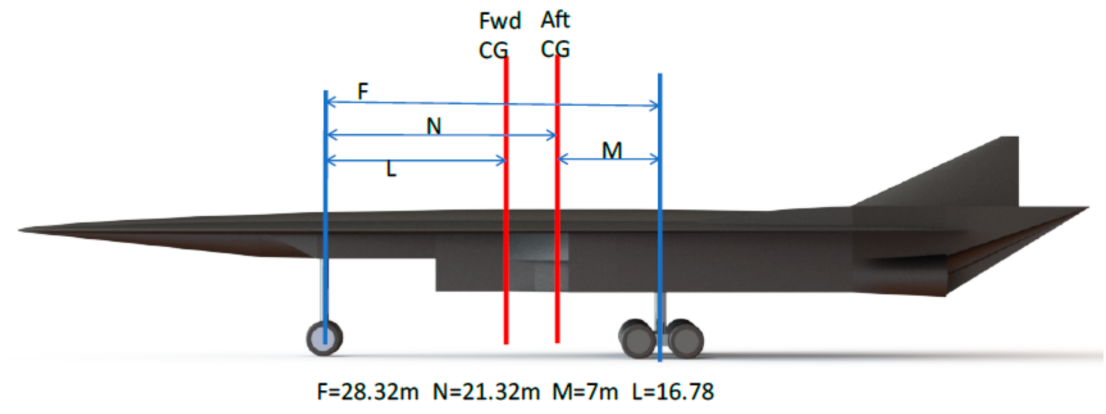

Figure 27. Landing gear locations.

Additionally, an iterative process was taken to choose an appropriate landing gear wheel layout to give the aircraft LG system a Load Classification Number (LCN). The LCN is a method established by the ICAO (International Civil Aviation Organization) where all major runways in the world are given an LCN number. For an aircraft to be used on a particular runway, the LG must be designed so that the LCN number does not exceed the runway LCN number the aircraft is intended to operate. The final LG wheel layout chosen was a dual twin tandem for the main gears (eight wheels per strut) and a dual twin for the nose gear (four wheels). Figure 28 below shows the relation between the LCN, tire loads and tire pressures; the aircraft is initially intended to operate from J.F.K Airport in New York, Heathrow Airport in London, Los Angeles International Airport, and Sydney International Airport. The LCN rating of the airports longest runways were investigated. The summary is shown in the Table 8.

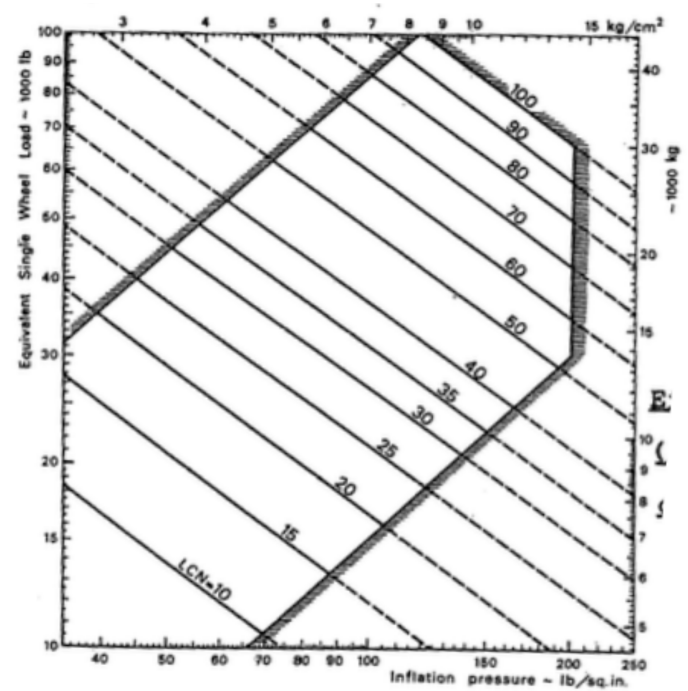

Figure 28. Effect of tire pressure and tire loads on LCN.

Table 8. Airport runway details.

\begin{tabular}{ccc}
\hline Airport & Runway Code & Information \\
\hline J.F.K & $13 / 31 \mathrm{~L}$ & LCN-94 Length-4423 m Surface type-Concrete \\
Heathrow & $09 \mathrm{R} / 27 \mathrm{~L}$ & LCN-83 Length-3902 m Surface type-Asphalt \\
Sydney & $16 \mathrm{R} / 34 \mathrm{~L}$ & LCN—67 Maximum tire pressure-217 psi Length-3962 m Surface type-Asphalt \\
\hline
\end{tabular}


It may be noted that the LCN number for the conceptual aircraft had to be a maximum value of 67 as it was Sydney airport that had the lowest LCN number. Sydney Airport also had a maximum pressure rating of 217 PSI. The maximum possible static load for a single wheel on the aircraft was calculated to be $16,000 \mathrm{~kg}$ / wheel Assuming the tire inflation pressure to be 150 PSI (typical transport aircraft wheel pressures), the LCN rating for the aircraft was obtained from the graph shown in Figure 28. The LCN rating for the conceptual aircraft with the wheel layout mentioned earlier is 50 . The reason the LG system was designed to be rated at $50 \mathrm{LCN}$ is to allow a $25 \%$ aircraft growth. As the maximum weights used in the calculations are based on initial estimates, it is common practice to have a safety margin of $25 \%$.

$$
\begin{gathered}
\text { Maximum static gear load using } 2 \text { struts }=\frac{\text { Gross Weight }(F-M)}{2 F} \\
\text { Maximum static nose gear load }=\frac{\text { Gross weight }(F-L)}{F} \\
\text { Minimum static nose gear load }=\frac{\text { Gross weight }(F-N)}{F}
\end{gathered}
$$

\subsubsection{Take-Off and Landing Distance}

Take-off and landing distance is an important part of aircraft design. The following formulas were used in the calculation of the take-off distance for the conceptual hypersonic transport aircraft designed:

$$
S=\frac{1}{2 B} \ln \frac{A}{A-B V_{T O}^{2}}
$$

where:

$$
\begin{gathered}
A=g\left(\frac{T_{0}}{W}-\mu\right) \\
B=\frac{g}{W}\left[\frac{1}{2} \rho S_{w}\left(C_{D g}-\mu C_{L g}\right)\right] \\
V_{T O}=\sqrt{\frac{2 W}{\rho S_{w} C_{L g}}}
\end{gathered}
$$

The take-off distance at estimated maximum take-off weight was calculated to be $2081.7 \mathrm{~m}$. However, the regulations set forth by regulatory bodies such as ICAO and FAA (Federal Aviation Administration) on transport category aircraft states that the aircraft must be able to take-off safely from the intended airport when there is one engine inoperative. Therefore, the original design that used three engines was scrapped and an extra turbojet engine integrated above the scramjet in an over under configuration. The new take-off distance is $3277 \mathrm{~m}$ using 750,000 $\mathrm{N}$ thrust when one of the engines remain inoperative.

The landing distance was calculated with the worst-case scenario in mind. It was assumed the aircraft would make an emergency landing soon after take-off with $90 \%$ of the maximum take-off weight. The approach speed of the aircraft was set to 1.3 times the stall speed:

$$
V_{s}=\sqrt{\frac{2 W}{\rho S_{W} C_{L \max }}}=65.2 \frac{\mathrm{m}}{\mathrm{s}}
$$

This would give an approach speed, $V_{A}=84.8 \mathrm{~m} / \mathrm{s}$. The landing distance was then calculated using the landing ground run distance formula shown below:

$$
S_{L}=\frac{1}{2 B} \ln \left[1-\frac{B}{A} V_{A}^{2}\right]
$$


The total landing ground run distance was calculated to be $1437.4 \mathrm{~m}$.

\subsubsection{Noise Analysis}

In this section, the impact of noise of the aircraft is analysed. Noise level (expressed in $\mathrm{dB}$ ) is given by the formula (Howe 1998; French 1971):

$$
L_{p}=20 \log \left(\frac{P}{P_{0}}\right)
$$

Value of $P_{0}$ is around $20 \mu \mathrm{Pa}$ and it corresponds to the threshold of human hearing. Equation (13) shows the sound level at a distance away from the source:

$$
L_{2}=L_{1}-\left|20 \log \left(\frac{r_{1}}{r_{2}}\right)\right|
$$

where $L_{1}$ is the noise level at the source in $\mathrm{dB}, r_{1}$ is the distance $L_{1}$ is measured from and $r_{2}$ is the distance $L_{2}$ is calculated for.

The noise level generated by the supersonic and hypersonic flight was first determined by the compressible charts and was then compared with the CFD results. Based on equations using the compressible flow charts, the designed conceptual aircraft will generate $125 \mathrm{~dB}$ of noise at cruise altitude at a speed of Mach 8 . The noise level will be dampened by the atmosphere and would reduce to $74.54 \mathrm{~dB}$. The analysis was also done for a flight speed of Mach 2 at an altitude of $15 \mathrm{~km}$. The sound level calculated at an altitude of $15 \mathrm{~km}$ was $151.7 \mathrm{~dB}$. This is because at lower speeds, the shock angle is increased for the same deflection angle. The increase in shock angle strengthens the shock, thus, higher dynamic pressures are generated.

Using the sound level calculated for Mach 2 at an altitude of $15 \mathrm{~km}$, the sound level on the ground was calculated to be $107.3 \mathrm{~dB}$. This level is higher than what the regulatory bodies currently permit over land, therefore, the aircraft would not be able to fly over land at supersonic speeds unless, in the future, new supersonic and hypersonic aircraft regulations increase the current noise level limits for such aircraft.

The static pressure increase across the shockwave at Mach 8 was also obtained in graph form from the 3-D aircraft CFD results. The shockwave's effect on the static pressure can be seen as a large spike in the graph. The static pressure increases to $0.76 \mathrm{~Pa}$ across the shockwave, up from the freestream pressure of $0.11 \mathrm{~Pa}$. The sound level calculated using this value is $124.6 \mathrm{~dB}$ which is 0.4 lower than the theoretical calculations.

\section{Conclusions}

The paper describes the detailed design and analysis of a conceptual hypersonic transport aircraft capable of Mach 8 cruise at $30 \mathrm{~km}$ altitude along with the hybrid engine integration. The aircraft design was based on conceptual aircraft design procedure and multiple design iterations were analysed to arrive at a final aircraft design that was relatively efficient at subsonic, supersonic and hypersonic flight conditions. A Sears-Haack body was implemented on the fuselage and a supercritical aerofoil with $1 \%$ thickness to chord ratio was chosen in the final design as these were the bodies with the minimum drag.

A supercritical aerofoil was chosen over conventional supersonic wedge aerofoils for added lift characteristics at subsonic conditions. The wedge aerofoil did not provide enough lift to achieve take-off at desired speeds and runway lengths. Additionally, due to the minimal thickness of the supercritical aerofoil, the thin leading edge did not create detached bow shocks.

Finally, the hybrid engine was integrated onto the aircraft and further analysed through CFD simulations. Results showed that the waverider geometry designed into the forebody of the aircraft during the engine integration process was effective in increasing the lift at hypersonic speeds. Drag 
analyses indicated that the thrust obtained from the scramjet with a reduction in thrust of $30 \%$ is enough to maintain cruise flight at Mach 8.

Author Contributions: C.A. was the principal researcher who conducted the detailed study and wrote the paper, assisted by A.A.S., who also edited the paper. A.P. conceived of the project, created the layout of the investigations, and checked the computational outcome of the resultant modelling effort and subsequent discussion. These authors contributed equally to this work.

Funding: This research received no external funding.

Conflicts of Interest: The authors declare no conflict of interest.

\section{References}

1. Committee on Hypersonic Technology for Military Applications. Hypersonic Technology for Military Application; Airforce Studies Board, National Research Council, National Academy Press: Washington, DC, USA, 1989.

2. European Space Agency. Available online: http://www.dailymail.co.uk/sciencetech/article-3686768 (accessed on 28 October 2016).

3. Gülçat, Ü. Fundamentals of Modern Unsteady Aerodynamics, 2nd ed.; Springer: Singapore, 2006; ISBN 978-981-10-0016-04.

4. Bauer, E. Physics of High-Temperature Air. Part 1. Basics; Technical Report; Institute for Defence Analyses: Alexandria, VA, USA, 1990. Available online: http://www.dtic.mil/dtic/tr/fulltext/u2/a229778.pdf (accessed on 13 November 2016).

5. Viviani, A.; Pezzella, G. Aerodynamic and Aerothermodynamic Analysis of Space Mission Vehicles; Springer: Cham, Switzerland, 2015; ISBN 978-3319139289.

6. Morreti, G.; Pandolfi, M. Entropy Layers. Comput. Fluids 1973, 1, 19-35. [CrossRef]

7. Murthy, S.N.B.; Curran, E.T. Scramjet Propulsion; Progress in Astronautics and Aeronautics; AIAA: Reston, VA, USA, 2001; Volume 189, ISBN 978-1-56347-322-7.

8. Javaid, K.H.; Serghides, V.C. Airframe propulsion integration methodology for waverider derived hypersonic cruise aircraft design concepts. J. Spacecr. Rocket. 2005, 42, 663-671. [CrossRef]

9. McClinton, C.R. High Speed/Hypersonic aircraft propulsion technology. In Advances on Propulsion Technology for High Speed Aircraft; Educational Notes, RTO-EN-AVT-150, Paper-1; NATO Research and Technology Organisation: Neuilly-sur-Seine, France, 2008; pp. 1-1-1-32.

10. Sinha, K. Shock-Boundary Layer Interaction (SBLI) Workshop on CFD Research and Applications; Indian Institute of Technology Bombay: Mumbai, India, May 2012.

11. Baidya, R.; Pesyridis, A.; Cooper, M. Ramjet nozzle analysis for transport aircraft configuration for sustained hypersonic flight. Appl. Sci. 2018, 8, 574. [CrossRef]

12. Neill, S.M.; Pesyridis, A. Modelling of supersonic combustion systems for sustained hypersonic flight. Energies 2017, 10, 1900. [CrossRef]

13. Sen, D.; Pesyridis, A.; Lenton, A. A scramjet compression system for hypersonic air transportation vehicle combined cycle engines. Energies 2018, 11, 1568. [CrossRef]

14. ANSYS. Ansys Fluent-Solver Theory Guide, Release 14.5 ed.; ANSYS: Canonsburg, PA, USA, 2012.

15. Lawrence, M. Drag Characteristics Obtained from Several Configurations of the Modified X-15-2 Airplane up to Mach 6.7 NASA Technical Memorandum; NASA Flight Research Center: Kern County, CA, USA, 1970.

16. Slater, W.J. Verification assessment of flow boundary conditions for CFD analysis of supersonic inlet flows. In Proceedings of the 37th Joint Propulsion Conference and Exhibit, Salt Lake City, UT, USA, 8-11 July 2001.

17. Roy, C.J.; Blottner, F.G. Review and assessment of turbulence models for hypersonic flows. Prog. Aerosp. Sci. 2006, 42, 469-530. [CrossRef]

18. Raymer, D. Aircraft Design: A conceptual Approach, 2nd ed.; American Institute of Aeronautics and Astronautics: Reston, VA, USA, 1992.

19. Palaniappan, K.; Jameson, A. Bodies having Minimum Pressure Drag in Supersonic Flow-Investigating Nonlinear Effects. In Proceedings of the 22nd Applied Aerodynamics and Conference and Exhibit, Providence, RI, USA, 16-19 August 2004. 
20. Harris, C.D. NASA Supercritical Airfoils: A Matrix of Family-Related Airfoils; NASA Technical Report, NASA-TP-2969; NASA Langley Research Center: Hampton, VA, USA, 1990.

21. UIUC Applied Aerodynamics Group. Available online: http://m-selig.ae.illinois.edu/ads/coord_database. html (accessed on 6 November 2016).

22. Roskam, J. Airplane Design, Part VII: Determination of Stability Control and Performance Characteristics: FAR and Military Requirements; DAR Corporation: Lawrence, KS, USA, 2002. 